Trinity College

Trinity College Digital Repository

Faculty Scholarship

2006

How Abundant is Pedogenic Magnetite? Abundance and Grain

Size Estimates for Loessic Soils Based on Rock Magnetic

Analyses

Christoph Geiss

Trinity College, christoph.geiss@trincoll.edu

C. William Zanner

University of Minnesota - Twin Cities

Follow this and additional works at: https://digitalrepository.trincoll.edu/facpub

Part of the Geophysics and Seismology Commons 


\title{
How abundant is pedogenic magnetite? Abundance and grain size estimates for loessic soils based on rock magnetic analyses
}

\author{
Christoph E. Geiss ${ }^{1}$ and C. William Zanner $^{2}$ \\ Received 14 June 2006; revised 8 October 2006; accepted 30 October 2006; published 7 December 2006.
}

[1] The upper soil horizons of many modern and ancient soils are enriched in fine-grained pedogenic ferrimagnetic minerals. We use three grain-size- and concentration-dependent proxies (anhysteretic remanent magnetization/isothermal remanent magnetization ratios, coercivity spectra derived from alternating field demagnetization of saturation isothermal remanent magnetization and hysteresis properties) to quantify the abundance and grain size of the pedogenic magnetic component. Our analyses of modern loessic soils from the midwestern United States show that relatively small additions $(2-10 \mathrm{vol} \%$ of the total ferrimagnetic component) of fine-grained (coarse superparamagnetic to fine pseudosingle domain) magnetite or maghemite are sufficient to explain the changes in concentration and grain-size-dependent properties observed in the upper soil horizons. Furthermore, the pedogenic components of all studied sites display a narrow range of magnetic properties, which argues for a common origin of these particles over a wide range of climatic conditions.

Citation: Geiss, C. E., and C. W. Zanner (2006), How abundant is pedogenic magnetite? Abundance and grain size estimates for loessic soils based on rock magnetic analyses, J. Geophys. Res., 111, B12S21, doi:10.1029/2006JB004564.

\section{Introduction}

[2] The upper horizons of many modern and buried soils have higher concentrations of ferrimagnetic minerals than the parent material from which they were originally derived. This change in magnetic properties (magnetic enhancement) was recognized early on [e.g., Le Borgne, 1955, 1960; Mullins, 1977, and references therein] and subsequent studies have documented magnetic enhancement in many loessic soils that developed under temperate climatic conditions [e.g., Feng et al., 1994; Forster and Heller, 1997; Heller and Liu, 1984; Kukla et al., 1988; Maher, 1986; $\ddot{O} z$ demir and Banerjee, 1982]. Building on these findings, numerous studies [e.g., Banerjee, 1994; Begét and Hawkins, 1989; Heller and Liu, 1986; Kukla, 1988; Maher and Thompson, 1992; Maher et al., 1994; Oches and Banerjee, 1996] suggest the use of soil magnetic properties as paleoclimatic or paleoenvironmental proxies.

[3] The pathways of pedogenic magnetite/maghemite formation are still under discussion, and several biotic and abiotic processes have been suggested [e.g., Dearing et al., 1997; Guyodo et al., 2006; Kletetschka and Banerjee, 1995; Kukla, 1988; Lu et al., 2000; Maher and Taylor, 1988; Mullins, 1977; Schwertmann, 1988; Singer and Fine, 1989]. In most studies magnetic enhancement is due to the neoformation of strongly magnetic ferrimagnetic minerals, such as magnetite or maghemite [Evans and Heller, 1994; Maher

\footnotetext{
${ }^{1}$ Department of Physics, Trinity College, Hartford, Connecticut, USA.

${ }^{2}$ Department of Soil, Water, and Climate, University of Minnesota, St. Paul, Minnesota, USA.

Copyright 2006 by the American Geophysical Union. 0148-0227/06/2006JB004564\$09.00
}

and Taylor, 1988]. This interpretation of magnetic enhancement is based on the observation of mineralogical changes (toward magnetite or maghemite) [e.g., Evans and Heller, 1994] and a shift to finer magnetic grain sizes [e.g., Zhou et al., 1990]. The pedogenic magnetic component is considered to extend from the single-domain $(\mathrm{SD} \approx 0.1-0.01 \mu \mathrm{m})$ into the superparamagnetic $(\mathrm{SP}<0.01 \mu \mathrm{m})$ grain size range [e.g., Heller and Evans, 1995; Maher, 1998, and references therein; Maher and Taylor, 1988]. These grain size estimates are based on increases in the ratio of anhysteretic remanent magnetization (ARM) to isothermal remanent magnetization (IRM), an indicator for the relative increase in small SD particles, as well as elevated values of frequencydependent susceptibility $\left(\chi_{\mathrm{FD}}\right)$, a proxy for the presence of ultrafine superparamagnetic particles. Small magnetic particles have been extracted from soils and have been investigated using electron microscopy by Maher et al. [1999], who produced similar particles under soil-like conditions [Taylor et al., 1987]. Measurements of the time dependence of IRM acquisition [Worm, 1999] also confirm the presence of ultrafine magnetic grains straddling the SDSP boundary in magnetically enhanced soil horizons (T. A. Machac et al., Time dependent IRM acquisition as a tool to quantify the abundance of ultrafine superparamagnetic magnetite in loessic soils, submitted to Geophysical Journal International, 2006, hereinafter referred to as Machac et al., submitted manuscript, 2006) and a recent study by Liu et al. [2005] quantified the grain size distribution of these superparamagnetic particles using the temperature dependence of $\chi_{\mathrm{FD}}$. The admixture of both SP and SD particles leads to increases in magnetic susceptibility, primarily driven by SP grains, and remanence parameters due to the formation of larger SD particles. 
[4] In his modeling of hysteresis parameters, however, Dunlop [2002a, 2002b] found little evidence for the presence of ultrafine SP particles in Chinese paleosol horizons. Furthermore, many well-developed modern loessic soils in the midwestern United States display two to threefold increases in IRM or magnetic susceptibility [e.g., Geiss and Zanner, 2006; Geiss et al., 2004] which suggests a significant addition of ferrimagnetic particles to the magnetically enhanced horizons. This addition of pedogenic remanence carrying ferrimagnets results in increases in $\mathrm{ARM} / \mathrm{IRM}$ ratios (up to 0.1 , but generally much lower) and $\chi_{\mathrm{FD}}$ values (generally $<5 \%$ ), which is modest compared to other sediments. In this paper we attempt to quantify the abundance of fine-grained (SD and SP) pedogenic ferrimagnetic minerals and address the following questions:

[5] 1. Can we obtain quantitative estimates of the abundance of pedogenically produced, ferrimagnets that are thermally stable at room temperature using common rock magnetic techniques? If so, are the results for the various techniques consistent, and how much of a fine-grained pedogenic component is required to produce the observed magnetic signal?

[6] 2. Is it possible to constrain the particle size distribution of the pedogenic component, and are the magnetic properties of this component site specific or relatively uniform between sites?

[7] Several authors have employed two-component mixing models to quantify the influence of the magnetic component on the rock magnetic signal or to directly quantify the amount of ferrimagnetic minerals produced during pedogenesis. Heller et al. [1993] used a combination of magnetic susceptibility data and ${ }^{10} \mathrm{Be}$ fluxes to reconstruct susceptibility fluxes for locations on the Chinese loess plateau during periods of loess deposition and soil formation. However, since magnetic susceptibility does not depend linearly on the concentration of magnetic minerals the authors did not attempt to quantify the amount of magnetite produced in soil horizons. Forster and Heller [1997] used a two end-member model to interpret hysteresis data. They found that loess paleosol sequences follow distinct magnetic enhancement paths but, again, did not attempt to quantify the amount of the pedogenically produced magnetic component. Evans and Heller [1994] employed, among other magnetic techniques, a simple analysis of IRM acquisition curves and found that pedogenic magnetic minerals across the Chinese loess plateau possess rather uniform magnetic properties and that relatively small amounts of pedogenic magnetite $(0.5 \mathrm{vol} \%$ of the sample) can explain the observed differences between paleosols and loess. Stockhausen [1998], Kruiver et al. [2001], and Heslop et al. [2002] developed more sophisticated techniques for the interpretation and unmixing of IRM acquisition curves based on cumulative log-Gaussian (CLG) distributions [Robertson and France, 1994] and applied their techniques to marine sediments [Kruiver and Passier, 2001], late Miocene red beds [Grygar et al., 2003] and loess deposits [Spassov et al., 2003]. Theoretical considerations by Heslop et al. [2004] showed that magnetic interactions can lead to a skewing of the coercivity distribution, which is incorporated in a more sophisticated unmixing algorithm devised by Egli [2003], who later analyzed a large number of natural samples [Egli,
2004] and extracted coercivity parameters that are characteristic for a variety of magnetic components.

[8] In our study we focused on well-characterized modern soil profiles developed in loess in the midwestern United States [Geiss and Zanner, 2006; Geiss et al., 2004] and evaluated three sets of grain-size- or coercivity-dependent magnetic parameters which we evaluated with either existing or newly developed two-component mixing models:

[9] 1. The ratio of ARM/IRM is a rapidly measured parameter that reflects the relative abundance of SD particles. We developed a simple two-component mixing model to quantitatively interpret ARM/IRM rations in terms of SD concentrations.

[10] 2. Hysteresis parameters, especially a plot of saturation remanence/saturation magnetization $\left(\mathrm{J}_{\mathrm{rs}} / \mathrm{J}_{\mathrm{s}}\right)$ versus coercivity of remanence/coercive force $\left(\mathrm{B}_{\mathrm{cr}} / \mathrm{B}_{\mathrm{c}}\right)$ (Day plot) [Day et al., 1977] are often used to estimate changes in bulk magnetic grain size. We apply a model developed by Dunlop [2002a] and attempt to quantify the addition of SD grains to the magnetically enhanced soil horizons.

[11] 3. The results of these two models are compared to alternating field demagnetization curves, which were fitted to cumulative lognormal distributions to isolate pedogenic and background components.

[12] Together with a careful magnetic characterization of the studied soil profiles, the answers to these questions might constrain the pathways of magnetic enhancement and improve our understanding of the links between soilforming factors and the soil magnetic signal, a vital prerequisite for using magnetic parameters as proxies for past environmental conditions.

\section{Methods}

\subsection{Site Selection}

[13] We studied modern soil profiles that developed in Peoria loess and are relatively undisturbed by recent human activity and erosion. Site selection and initial pedologic and magnetic analyses are described in detail by Geiss and Zanner [2006]. All our sites are well-drained mollosols that formed in loess in stable upland positions. Miriam Cemetery (MIR 04-A) is located on an upland loess plain in SW Nebraska $\left(41.01^{\circ} \mathrm{N}, 100.66^{\circ} \mathrm{W}\right)$. The presettlement vegetation was shortgrass prairie, the mean annual precipitation at the site is $490 \mathrm{~mm} / \mathrm{yr}$. Prairie Pines (PRA 02-A) is located on a piece of native tallgrass prairie near Lincoln, Nebraska $\left(40.84^{\circ} \mathrm{N}, 96.56^{\circ} \mathrm{W}\right)$. The soil developed in gently rolling uplands, the mean annual precipitation is $720 \mathrm{~mm} / \mathrm{yr}$. Mount Calvary Cemetery (MTC 03-A) is located in the Iowa loess hills $\left(40.87^{\circ} \mathrm{N}, 95.42^{\circ} \mathrm{W}\right)$, and the sampled soil developed in a gently rolling upland surface. The mean annual precipitation at the site is $840 \mathrm{~mm} / \mathrm{yr}$. Honey Creek Conservation Area (HON 03-A) is located in Central Missouri on the Missouri loess bluffs $\left(39.95^{\circ} \mathrm{N}, 94.97^{\circ} \mathrm{W}\right)$. The core was taken from a wooded, level upland area. The mean annual precipitation of the site is $910 \mathrm{~mm} / \mathrm{yr}$. Davisdale Conservation Area (DAV 03-A) is located $5 \mathrm{~km}$ north of the Missouri River $\left(39.04^{\circ} \mathrm{N}, 92.63^{\circ} \mathrm{W}\right)$. The soil here developed in loess on forested uplands. Mean annual precipitation of the site is $970 \mathrm{~mm} / \mathrm{yr}$. The locations of the sites discussed in this study, as well as the remaining sites of our transect are shown in Figure 1. 


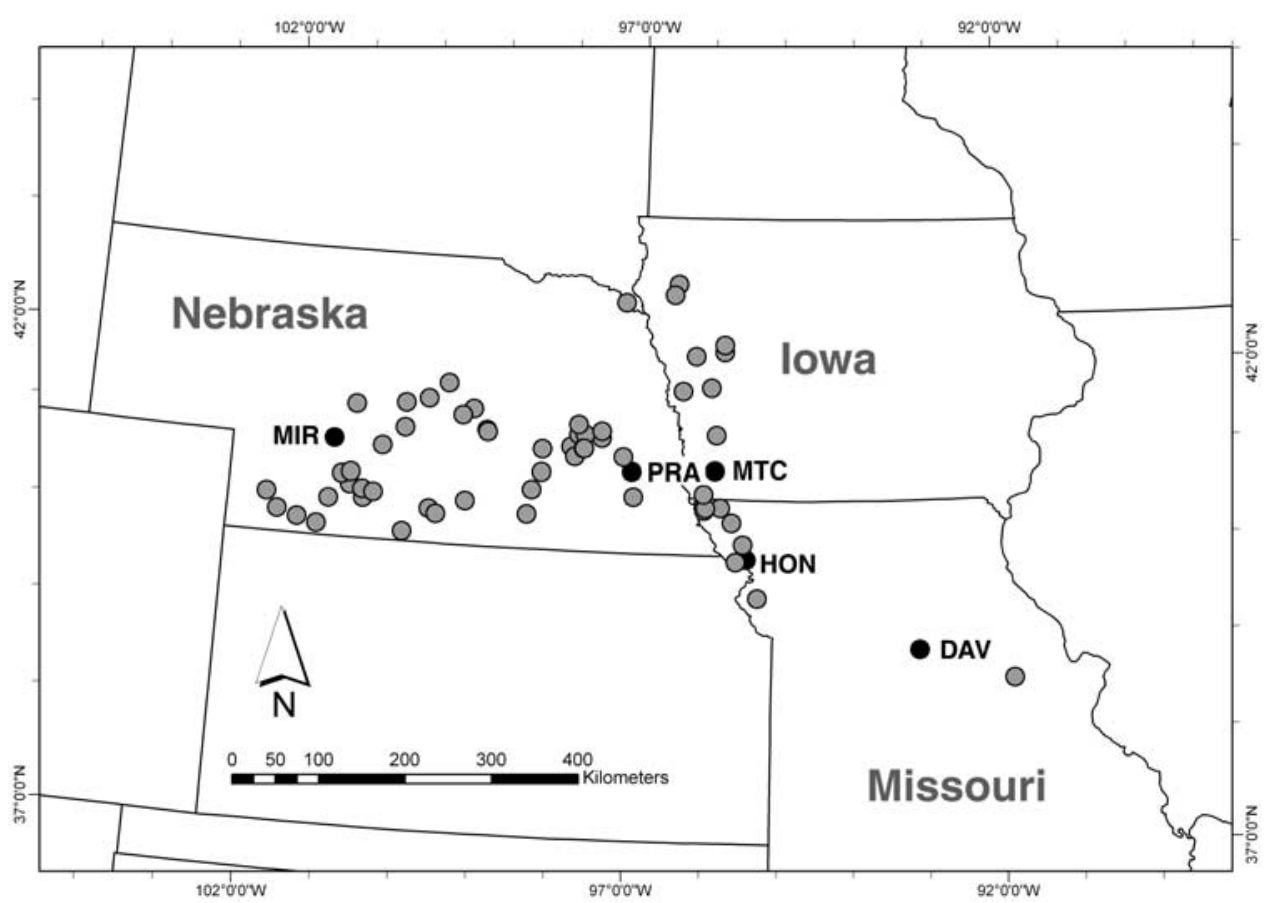

Figure 1. Map of all sites in our soil transect across Nebraska, Iowa, and Missouri. Sites discussed in this study are indicated (solid circles) and labeled MIR, Miriam cemetery; PRA, Prairie Pines; MTC, Mount Calvary cemetery; HON, Honey Creek conservation area; DAV, Davisdale Conservation Area.

\subsection{Sample Preparation}

[14] All sites were sampled using a truck-mounted hydraulic soil probe equipped with a 3 in $(7.5 \mathrm{~cm})$ diameter core barrel. Cores were described using standard Natural Resources Conservation Service terminology [Soil Survey Division Staff, 1993] and subsampled into small plastic bags in the field. The sampling interval was $5 \mathrm{~cm}$ for horizons that showed soil development and $10 \mathrm{~cm}$ for $\mathrm{C}$ horizon material. For further magnetic analyses, samples were air dried, gently crushed by hand, passed through a $2 \mathrm{~mm}$ sieve to remove root fragments, homogenized and filled into weakly diamagnetic plastic boxes of $5.3 \mathrm{~cm}^{3}$ volume. For low-temperature analyses a smaller amount of sample (approximately $200 \mathrm{mg}$ ) was filled in a polycarbonate capsule and mounted on a weakly diamagnetic drinking straw. All magnetic analyses were performed on bulk samples.

\subsection{Remanence Parameters}

[15] ARM was acquired in a peak alternating field of $100 \mathrm{mT}$ and a $50 \mu \mathrm{T}$ bias field, IRM was acquired in a $100 \mathrm{mT}$ DC field. Both remanence parameters were measured using a $2 \mathrm{G}$ cryogenic magnetometer (model 706-R) at the Institute for Rock Magnetism at the University of Minnesota. Alternating field (AF) demagnetization curves were measured for a selected subset of samples. These samples acquired an IRM in a pulsed field of $2.5 \mathrm{~T}$ imparted by a ASC Scientific IM-10-30 pulse magnetizer, followed by AF demagnetization up to a peak field of $300 \mathrm{mT}$ using a Magnon International AFD-300 demagnetizer. Remanence values were measured using an AGICO JR-6 spinner magnetometer.

\subsection{Hysteresis Loops}

[16] Hysteresis loops were measured using a Princeton Applied Research vibrating sample magnetometer, modified by the Institute for Rock Magnetism. The peak field was $1.25 \mathrm{~T}$, and the measurement included the determination of the coercivity of remanence $\left(\mathrm{B}_{\mathrm{cr}}\right)$.

\subsection{Frequency-Dependent Susceptibility}

[17] Frequency-dependent susceptibility $\left(\chi_{\mathrm{FD}}\right)$ was measured for a few samples to estimate the relative abundance of SP particles. These measurements were performed using a modified Bartington MS2b dual frequency sensor at frequencies of $470 \mathrm{~Hz}\left(\chi_{\mathrm{lf}}\right)$ and $4700 \mathrm{~Hz}\left(\chi_{\mathrm{hf}}\right)$ and $\chi_{\mathrm{FD}}$ was calculated as

$$
\chi_{F D}=\frac{\chi_{l f}-\chi_{h f}}{\chi_{l f}} 100
$$

High- and low-frequency measurements were repeated five times, which allowed which allowed us to estimate an error for the reported values of $\chi_{\mathrm{FD}}$.

\subsection{Data Analysis}

[18] We developed a simple, two-component mixing model to estimate fine (SD) and coarse (pseudo-single domain (PSD), multidomain (MD)) fractions based on ARM/IRM ratios. Assuming that ARM and IRM are determined by these two fractions we can write

$$
\begin{aligned}
& \mathrm{IRM}=\mathrm{IRM}_{\mathrm{SD}}+\mathrm{IRM}_{\mathrm{MD}}=J_{S} \alpha_{\mathrm{ISD}} f_{\mathrm{SD}}+J_{\mathrm{S}} \alpha_{\mathrm{IMD}}\left(1-f_{\mathrm{SD}}\right) \\
& \mathrm{ARM}=\mathrm{ARM}_{\mathrm{SD}}+\mathrm{ARM}_{\mathrm{MD}}=J_{S} \alpha_{\mathrm{ASD}} f_{\mathrm{SD}}+J_{S} \alpha_{\mathrm{AMD}}\left(1-f_{\mathrm{SD}}\right)
\end{aligned}
$$




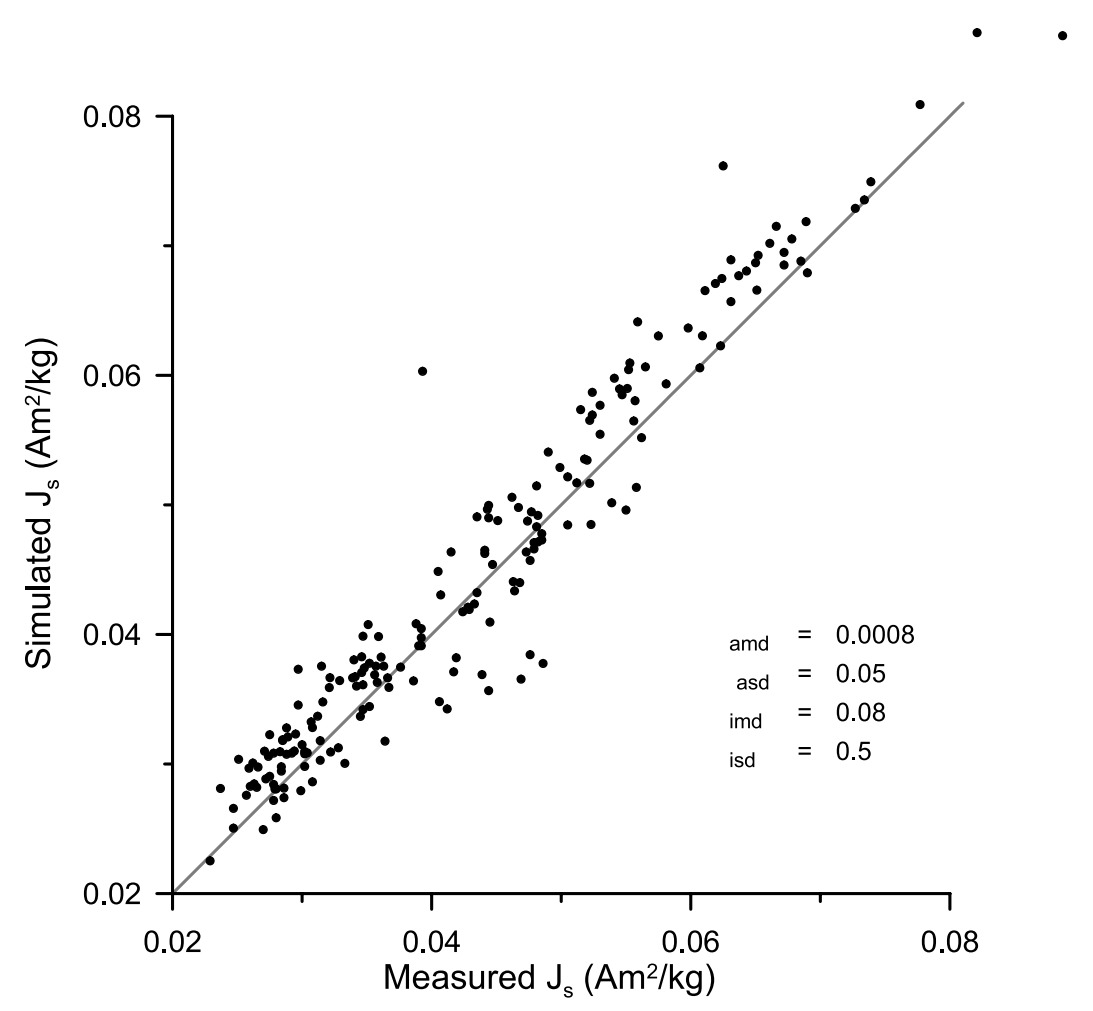

Figure 2. Scatterplot of $J_{S}$ values simulated through ARM/IRM two-component mixing model versus $\mathrm{J}_{\mathrm{S}}$ values obtained from hysteresis data. The remanence acquisition parameters used in the model are listed in Table 1.

where ARM (IRM) $)_{\mathrm{SD}(\mathrm{MD})}$ is the component of ARM (IRM) due to SD and MD (includes PSD and MD) particles, respectively; $f_{\mathrm{SD}}$ is the abundance of SD particles (ranging from 0 to 1$), \alpha_{\mathrm{ASD}}$ is the ARM acquisition efficiency for SD particles, $\alpha_{\mathrm{AMD}}$ is the ARM acquisition efficiency for MD particles. $\alpha_{\text {ISD }}$ and $\alpha_{\text {IMD }}$ are the IRM acquisition efficiencies for $\mathrm{SD}$ and $\mathrm{MD}$ particles, respectively. The two equations for IRM and ARM can be solved for $f_{\mathrm{SD}}$ and yield

$$
f_{\mathrm{SD}}=\frac{\mathrm{IRM} \alpha_{\mathrm{AMD}}-\mathrm{ARM} \alpha_{\mathrm{IMD}}}{\operatorname{IRM}\left(\alpha_{\mathrm{AMD}}-\alpha_{\mathrm{ASD}}\right)+\operatorname{ARM}\left(\alpha_{\mathrm{ISD}}-\alpha_{\mathrm{IMD}}\right)}
$$

[19] The IRM acquisition efficiencies $\alpha_{\text {ISD }}$ and $\alpha_{\text {IMD }}$ are relatively well constrained, where $\alpha_{\mathrm{ISD}}=\mathrm{J}_{\mathrm{rs}} / \mathrm{J}_{\mathrm{s}} \approx 0.5$ and $\alpha_{\text {IMD }}<0.05$ [Day et al., 1977]. ARM acquisition efficiencies are known to a lesser extent, but experience from lake sediments and soils has shown that for sediment dominated by coarse grained $\mathrm{MD}$ and PSD ferrimagnets $\mathrm{ARM} / \mathrm{IRM} \approx$
0.01 , while lake sediments with high concentrations of SD particles can reach ARM/IRM ratios up to $0.15-0.20$ [e.g., Geiss et al., 2003]. The observed range of ARM/IRM ratios may serve as a constraint for ARM acquisition efficiencies.

[20] It should be noted that equation (3) is independent of $\mathrm{J}_{\mathrm{S}}$, which can be used to test the validity of our model by predicting $\mathrm{J}_{\mathrm{S}}$ via equation (2) and comparing it to $\mathrm{J}_{\mathrm{S}}$ obtained from hysteresis measurements. This comparison serves as an additional constraint for the ARM and IRM acquisition efficiencies.

[21] Hysteresis data were plotted on a diagram of saturation remanent magnetization/saturation magnetization $\left(\mathrm{J}_{\mathrm{rs}} /\right.$ $\left.\mathrm{J}_{\mathrm{s}}\right)$ versus coercivity of remanence/coercive force $\left(\mathrm{B}_{\mathrm{cr}} / \mathrm{B}_{\mathrm{c}}\right)$ (Day diagram [Day et al., 1977]), and we used the mixing models of Dunlop [2002a] for (P)SD-MD and SP-MD mixtures to interpret our data. Our samples plot closely toward the MD field, and the resulting mixing lines are indistinguishable for SD-MD and SP-MD mixtures. With good evidence for the presence of SD particles in the

Figure 3. Magnetic properties for site MIR 04-A (Miriam Cemetery). (a) Unconstrained CLG analysis of IRM demagnetization curves for site MIR 04-A. (top) Coercivity spectrum for topmost sample (solid circles), the two CLG components (pedogenic, solid curve; background, dashed curve), and the sum of the two components (shaded curve) are shown. Vertical scale of all gradient data is constant throughout Figures 3-6 and is shown for the topmost sample only. For clarity, only the two modeled components are shown for the remaining samples of the soil profile. (b) Constrained CLG analysis for the same samples as shown in Figure 3a. Gradient data for all samples (solid circles) and total results of the unconstrained (shaded curve) and constrained (solid curve) CLG modeling are shown. (c) ARM/IRM ratios shown for comparison with CLG analyses. The table lists the abundance estimates for the pedogenic component $f_{\text {ped }}$ as a fraction of the total remanence carrying ferrimagnetic component. Our estimates are based on the listed magnetic grain size proxies. For further, information see text. 


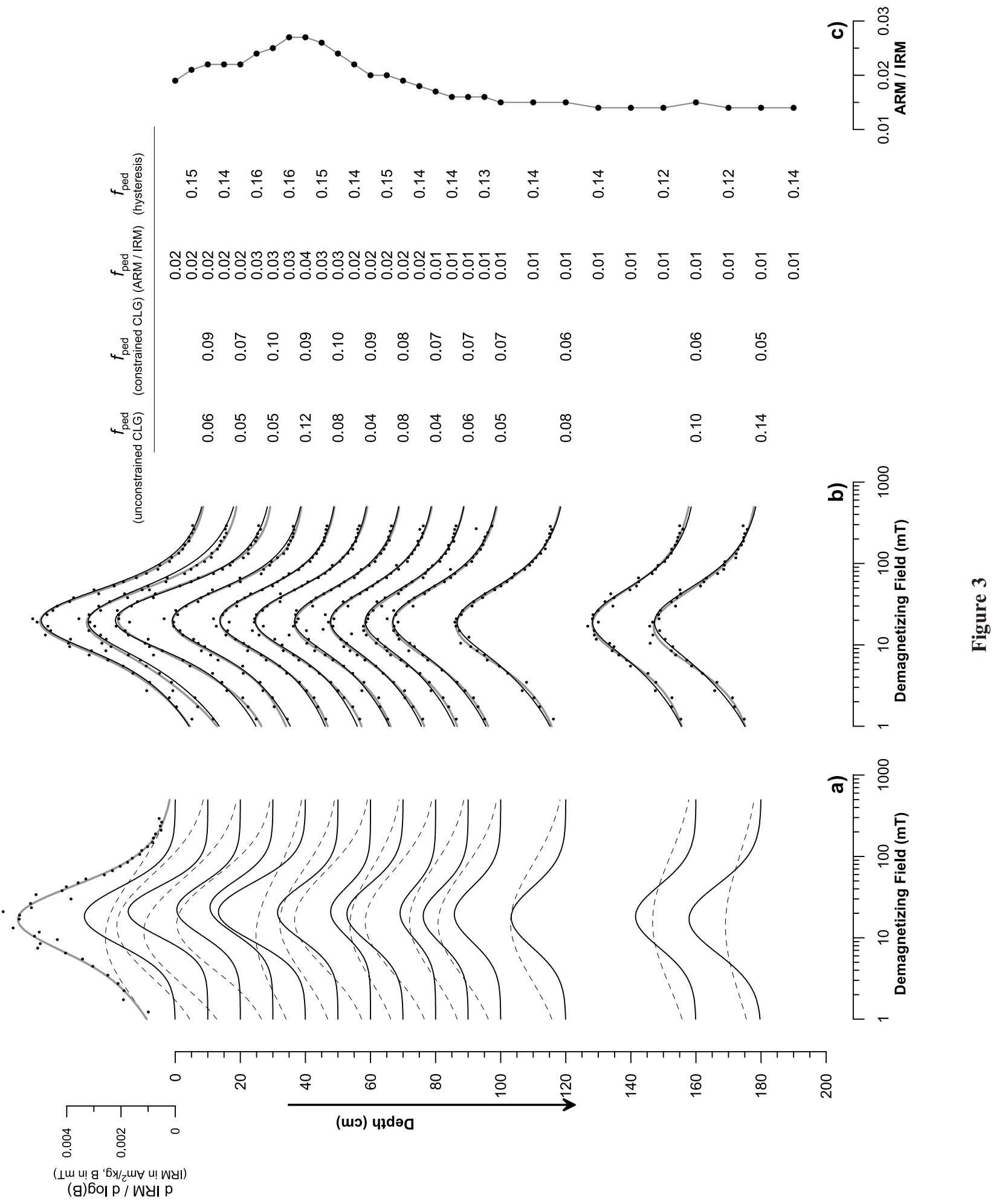




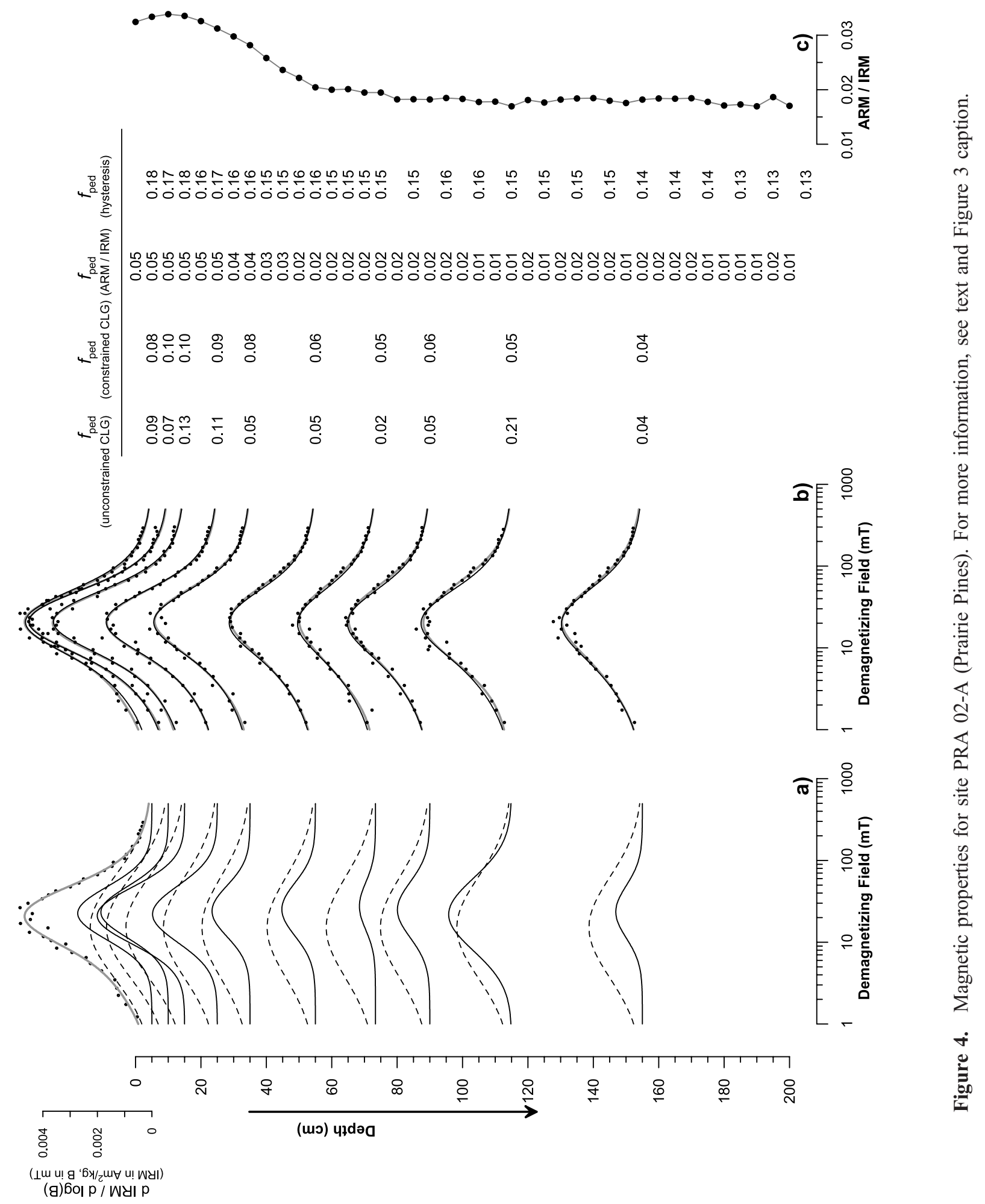




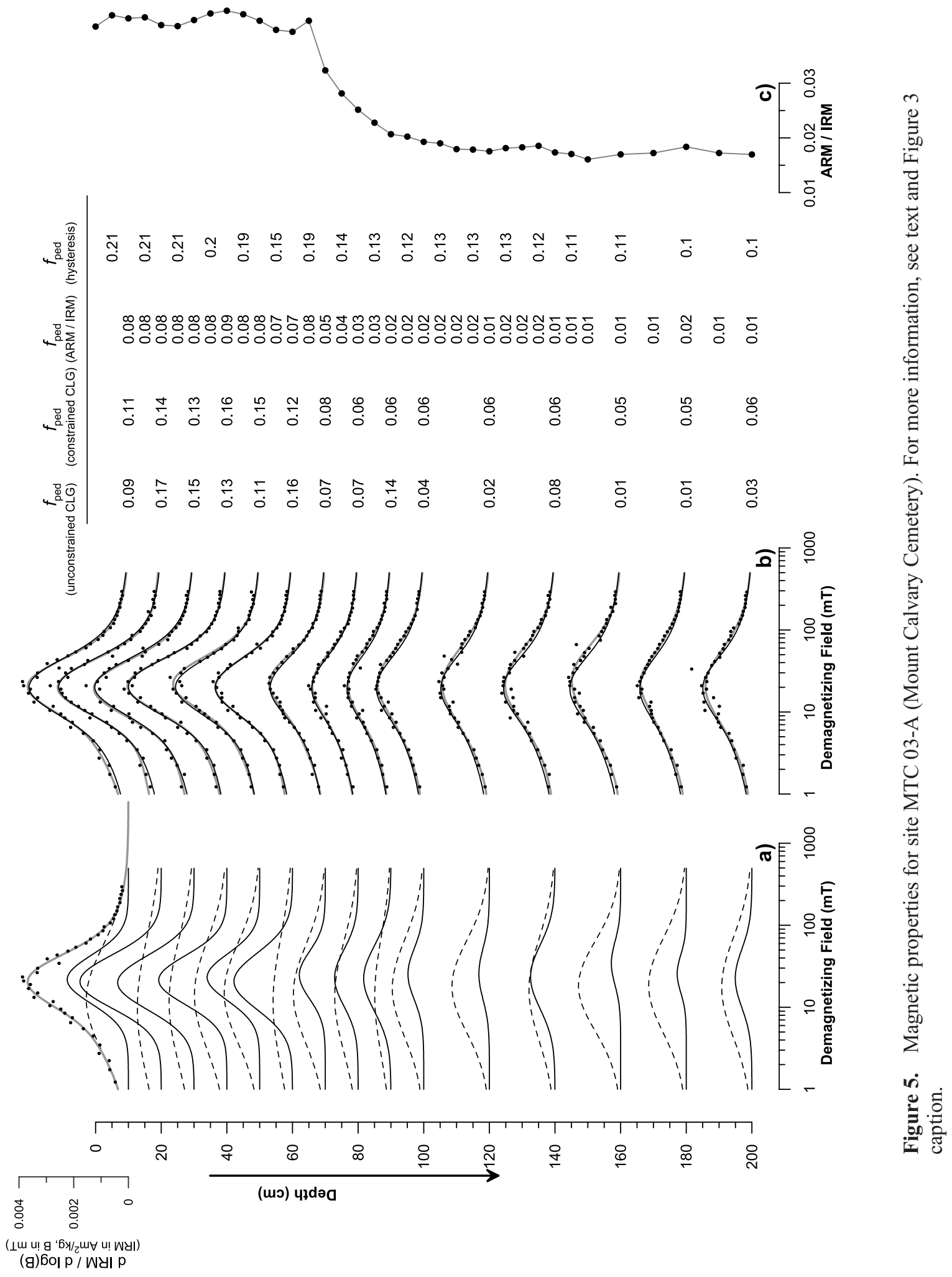




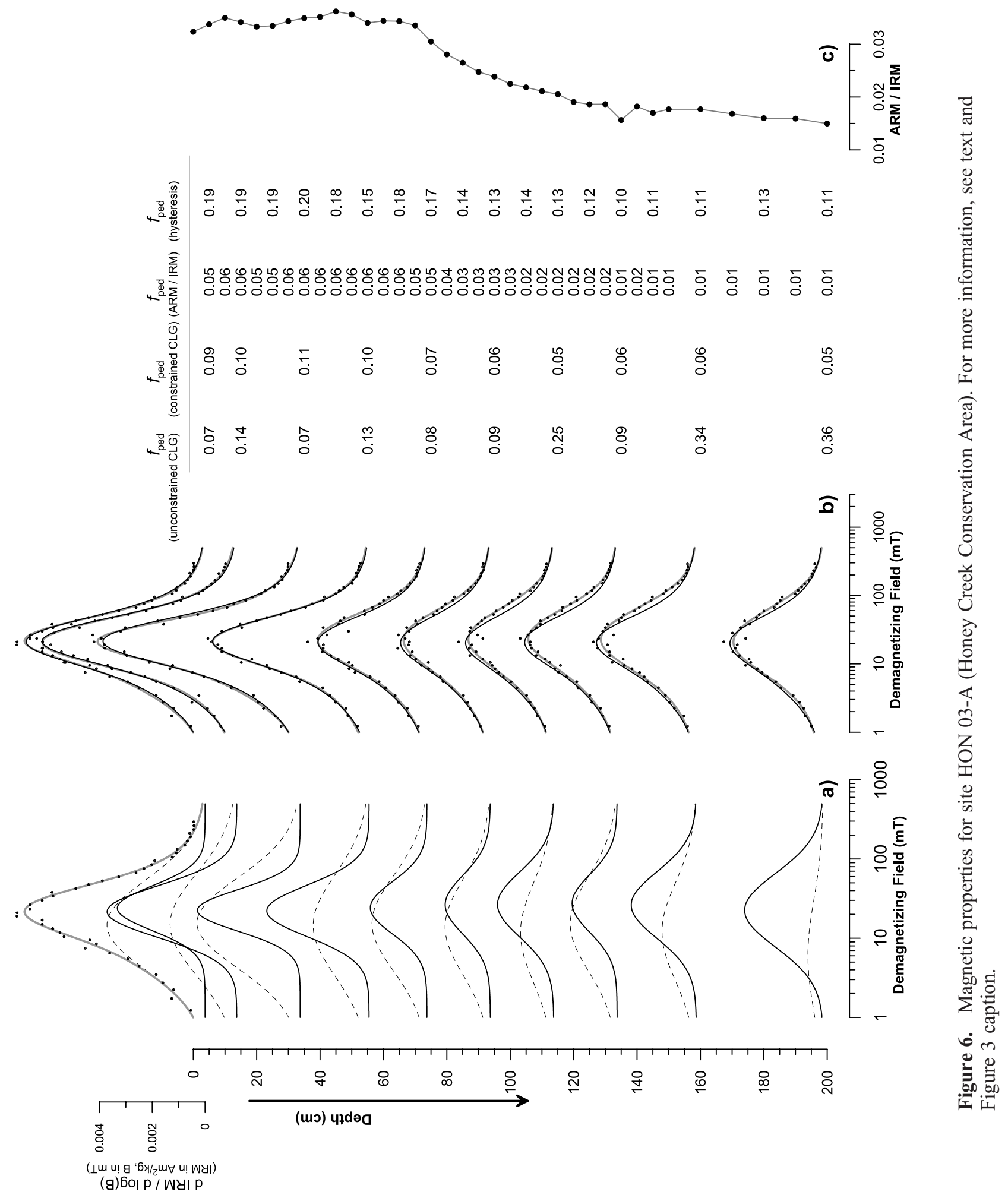


magnetically enhanced soil horizons we limited ourselves to (P)SD-MD mixing models.

[22] To measure coercivity spectra, samples acquired a saturation isothermal remanent magnetization (SIRM) in a pulsed field of $2.5 \mathrm{~T}$ and were then subjected to stepwise AF demagnetization. The derivatives of the AF demagnetization curves were fitted to cumulative log-Gaussian distributions (CLG) [Robertson and France, 1994; Stockhausen, 1998] rather than using the more elaborate distribution suggested by Egli [2004].

$$
\operatorname{CLG}(B, M, B h, D p)=\frac{M}{D p \sqrt{2 \pi}} \exp \left[-\frac{(\log B-\log B h)^{2}}{2 D p^{2}}\right]
$$

The use of mathematically simpler CLGs led to robust fit results without the need for any smoothing algorithm. The results were easily interpreted in terms of $\log$ mean coercivity $(\log \mathrm{Bh})$, where $\mathrm{Bh}$ is given in $\mathrm{mT}$, distribution width $\mathrm{Dp}$, and saturation remanence M. CLG fitting was accomplished using a simple fitting program written in Mathematica. To estimate the error of our fit parameters, we applied a bootstrapping algorithm, randomly dropping $10 \%$ of the demagnetization data before each fitting procedure. The process was repeated 100 times, and for each fit the standard deviation between the fit and the original data was calculated. Fit results were sorted in order of increasing standard deviations, and averages and standard deviations were calculated for the peak position (Bh), distribution width $(\mathrm{Dp})$ and magnitude $(\mathrm{M})$ of the distribution using the 20 best fits.

[23] Our simple mixing models do not consider magnetic interactions, which may lower ARM values [e.g., Yamazaki and Ioka, 1997] or skew the coercivity distribution as observed for some samples by Egli [2003] and theoretically confirmed by Heslop et al. [2004]. However, for most natural samples magnetic interactions are likely to play a minor role as overall concentrations of strongly magnetic minerals are low and the particles are generally well dispersed [Egli, 2004]. This is likely true for the soils analyzed in this study. ARM/IRM ratios are highest in the magnetically enhanced horizons, where the concentration of ferrimagnetic grains and potential for magnetic interactions are highest. Furthermore, our modeling of ARM/IRM ratios requires only one set of ARM acquisition efficiencies (see Figure 2) to describe ARM/IRM ratios for soil and loess samples displaying a wide range of magnetic susceptibility and remanence values. A comparison of our CLG fits with similar analyses that allow for skewed coercivity distributions [Egli, 2004] on Chinese modern and buried soils yields very similar distribution parameters, thus justifying our simplified approach.

\section{Results and Discussion}

\subsection{ARM/IRM Ratios}

[24] We applied our two-component mixing model to ARM and IRM data measured for eleven loessic soil profiles from the midwestern United States. The observed increases in IRM as well as ARM/IRM ratios require only relatively small additions of fine-grained material (varying
Table 1. Acquisition Efficiencies Used in ARM/IRM TwoComponent Mixing Model

\begin{tabular}{cc}
\hline Acquisition Efficiency & Numerical Value \\
\hline$\alpha_{\text {amd }}$ & 0.0008 \\
$\alpha_{\text {imd }}$ & 0.08 \\
$\alpha_{\text {asd }}$ & 0.05 \\
$\alpha_{\text {isd }}$ & 0.5 \\
\hline
\end{tabular}

from 2 to 10 vol $\%$ of the ferrimagnetic component) to the magnetically enhanced soil horizons. The tables in Figures 3-6 list the modeling results for four selected sites from our transect ( $\left.f_{\text {ped }} \mathrm{ARM} / \mathrm{IRM}\right)$. All ARM/IRM mixing models utilized the same set of acquisition efficiencies listed in Table 1.

[25] Since the pedogenic component is always seen against a background of magnetic material inherited from the parent material it is more useful to express the amount of pedogenic material $\left(f_{\text {ped }}\right)$ as a fraction of the ferrimagnetic minerals present in sample rather than normalizing it by the volume or mass of the entire sample. Throughout this paper all pedogenic fractions $f_{\text {ped }}$ will therefore be calculated as a fraction of the ferrimagnetic component.

[26] Figure 2 shows $\mathrm{J}_{\mathrm{S}}$ values simulated through our model for all analyzed sites and compares them to $\mathrm{J}_{\mathrm{S}}$ values obtained from hysteresis measurements. It is remarkable that one set of acquisition efficiencies (Table 1) does a reasonable job explaining ARM/IRM ratios across our entire transect of sites, even though the studied soil profiles developed under a steep precipitation gradient $(<500 \mathrm{~mm} / \mathrm{yr}$ in SW Nebraska to $\sim 1000 \mathrm{~mm} / \mathrm{yr}$ in central Missouri). Our model results suggest a single, rather homogenous pedogenic phase responsible for the magnetic enhancement observed at all sites.

\subsection{IRM Demagnetization Curves}

[27] The presence of a homogenous pedogenic phase is confirmed by our analysis of magnetic coercivity spectra (Figures 3a, 3b, 4a, 4b, 5a, 5b, 6a, and 6b). We measured coercivity spectra for samples from five modern soil profiles, and the spectra were analyzed by fitting the data to two or three CLG distributions. Our analysis showed that a two-component model fits most spectra and that a three component fit offers only slight improvements in fit quality, while producing many unrealistic solutions (negative values of $\mathrm{M}$, extremely narrow distributions that focus on one or two noisy data points). Since the remaining analyses presented in this study infer two-component mixing models we chose to focus our analyses on the results of a twocomponent CLG mix.

[28] Figures 3a, 4a, 5a, and 6a show the results of our analyses for four soil profiles. The coercivity distributions for selected samples are plotted as a function of depth, according to their position in the soil profile. The topmost curve shows the measured coercivity data (solid circles), the two modeled coercivity distributions (dashed curve, solid curve) as well as the sum of the two distributions (shaded curve). For clarity only the two coercivity distributions (dashed curve, solid curve) are shown for the remaining samples of the soil profile. To facilitate comparison between samples, all distributions are plotted using the same scale $(\Delta \mathrm{IRM} / \Delta \log \mathrm{B}$, where IRM is measured in $\mathrm{A} \mathrm{m} / 2 \mathrm{~kg}$ and $\mathrm{B}$ 


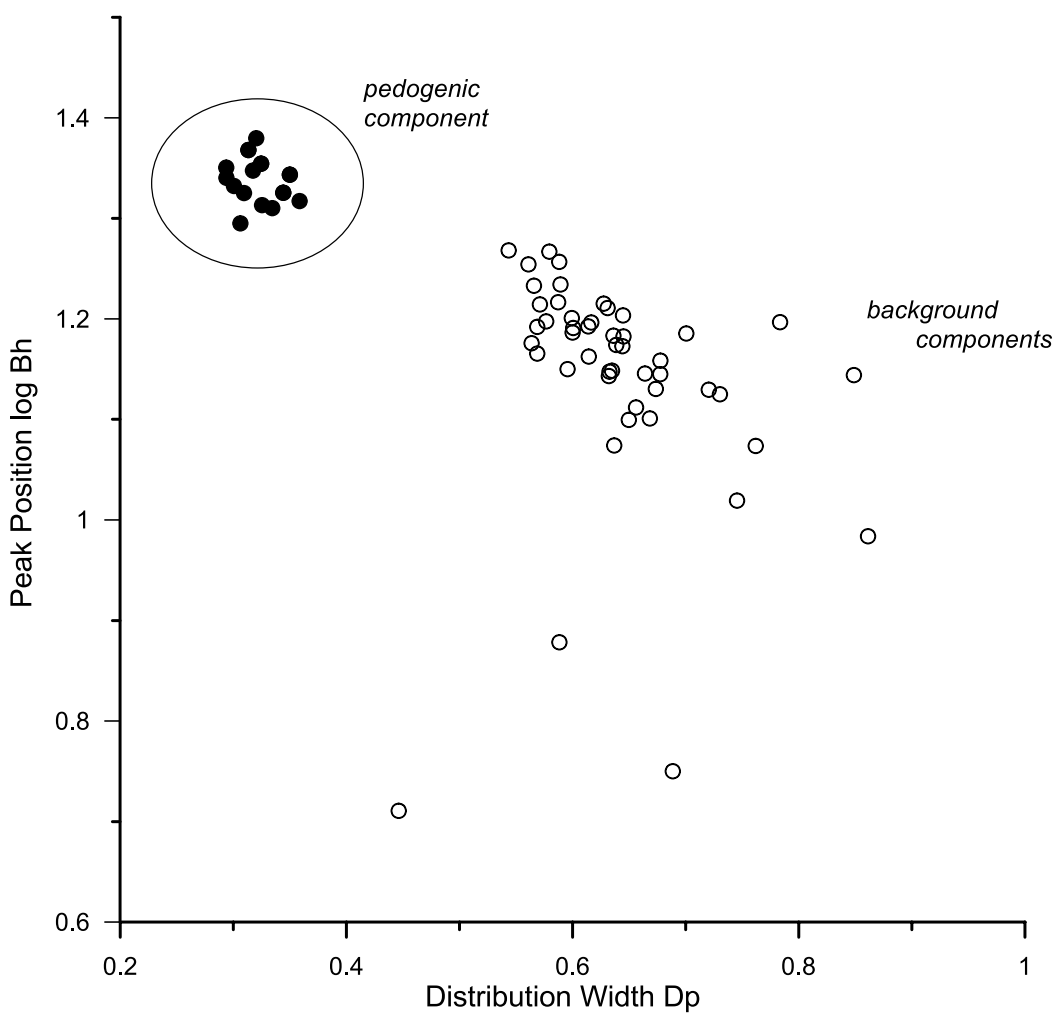

Figure 7. Summary of CLG parameters for pedogenic and background components for soil profiles shown in Figures 3-6. Magnetically enhanced profiles are denoted by solid circles, samples from the parent material are shown with open circles. Distribution values are listed in Table 2 . Bh is measured in $\mathrm{mT}$.

is given in $\mathrm{mT}$ ) which is indicated for the topmost sample and is kept constant for Figures 3-6.

[29] The CLG components shown in Figures 3-6a represent the best fit to the measured coercivity data, without any constraints on $\mathrm{M}, \mathrm{Bh}$, or $\mathrm{Dp}$ (with the exception of requiring $\mathrm{M}>0$ ). Close inspection of the distributions shows that the magnetically enhanced samples (near the top of the profile and characterized by higher ARM/IRM ratios (see Figures 3-6d) show an increased abundance of a medium coercivity component (solid curve) centered around fields of $20 \mathrm{mT}(\log \mathrm{Bh}=1.28-1.33)$ with relatively narrow distribution widths $(\mathrm{Dp}=0.25-0.38)$. This component is superimposed onto a variable background component (dashed curve). The magnetic properties of this medium coercivity component are remarkably similar throughout our study area. Figure 7 displays its distribution properties $\log \mathrm{Bh}$ and $\mathrm{Dp}$ (solid circles) as well as the distribution properties of the background component (open circles). The presence of this component in all magnetically enhanced soil horizons and its relatively minor role in the unaltered lower soil horizons suggests that this component is of pedogenic origin.

[30] Similar analyses of ARM and IRM demagnetization curves of Chinese and Swiss soils which use generalized probability density functions [Egli, 2004] yield coercivity distributions for the pedogenic component with very similar distribution properties $(\log \mathrm{Bh}=1.2-1.4, \mathrm{Dp}=0.25-0.4)$. Evans and Heller [1994] measured IRM demagnetization curves for several loess/paleosol couples and isolated a pedogenic component with median destructive fields of about $20 \mathrm{mT}$, very similar to the results obtained by Egli and our study. These similar magnetic properties argue for a common origin of this pedogenic component in the loessic soils of our study area, even though climatic conditions and corresponding biota, two of Jenny's [1941] soil forming factors, vary widely from shortgrass prairie in SW Nebraska to tallgrass prairie/forest parkland toward the moister end of our transect in central Missouri.

[31] Assigning a pedogenic origin to this component and using the remanence acquisition efficiencies listed in Table 1 we can estimate the abundance of the pedogenic component:

$$
f_{\text {ped }}=\frac{M_{\text {ped }} / \alpha_{\text {isd }}}{M_{\text {ped }} / \alpha_{\text {isd }}+M_{\text {background }} / \alpha_{\text {imd }}}
$$

Here $\mathrm{M}_{\text {ped }}$ and $\mathrm{M}_{\text {background }}$ are the remanence contributions due to the pedogenic and background components, respectively. The results of these estimates are shown in the tables associated with Figures 3-6 ( $f_{\text {ped }}$ unconstrained CLG). The increases in ARM/IRM are mirrored by elevated values of $f_{\text {ped }}$, however, largely to larger changes in the background component (dashed curve). $f_{\text {ped }}$ values, which track relative changes, do not decrease consistently in the unaltered parent material.

[32] Except for requiring positive values for $M$, the distribution parameters used in the CLG fits shown in Figures 3-6a are not constrained in any way. This is 
different from the two-component mixing models used to interpret ARM, IRM, and hysteresis data, where only mixtures of two distinct magnetic end-members are considered. To compare our analyses of IRM demagnetization curves to these models, we next consider two-component mixtures for the analysis of coercivity distributions. Table 2 shows the CLG parameters for the pedogenic and background components for all measured samples from sites Miriam Cemetery (MIR 04-A), Prairie Pines (PRA 02-A), Mount Calvary Cemetery (MTC 03-A), and Honey Creek Conservation Area (HON 03-A). To estimate Bh and Dp for the pedogenic component, we averaged $\mathrm{Bh}$ and $\mathrm{Dp}$ values of for the pedogenic component using data from magnetically enhanced horizons only. Bh and Dp values of the background component were obtained by averaging over all samples from one site. The samples used for the averaging process are indicated in bold in Table 2 . We then reanalyzed all coercivity data using the average distribution parameters of the pedogenic and background component, leaving $\mathrm{M}_{\text {ped }}$ and $\mathrm{M}_{\text {background }}$ as the only free variables. The results of these two-component fits are shown in Figures 3-6b (solid curve). To compare the quality of the fit, we also show the result of the previous unconstrained fits for all samples (shaded curve, not shown in Figures 3-6a). For clarity we only show the sum of the two components, but it is clear that the constrained two-component fit still provides a good approximation of the measured coercivity data (solid circles) as for many samples both fits plot almost on top of each other.

[33] The resulting abundances of the pedogenic component are listed in the tables in Figures $3-6\left(f_{\text {ped }}\right.$ constrained CLG) and can be compared to the mixing results from the ARM/IRM analyses ( $f_{\text {ped }}$ ARM/IRM). Comparing the results of the two models reveals that our analysis of IRM demagnetization curves yields consistently higher estimates of the pedogenic component, but the results of the two analyses correlate well with each other as shown in Figure 8. The observed discrepancies are not surprising as the two techniques are likely to respond to slightly different grain size/coercivity fractions. While increased ARM/IRM ratios are indicative of particles spanning a relatively small grain size range (see summary by Hunt et al. [1995a, Figure 15]), the pedogenic component obtained from CLG analyses is likely to represent a broader grain size distribution, thus resulting in larger estimates for the abundance of pedogenic magnetic minerals.

\subsection{Hysteresis Data}

[34] Hysteresis data, when plotted on a Day diagram [Day et al., 1977], follow a grain size trend that is consistent with our analyses of remanence data. Figure 9 shows a series of coercivity spectra from Mount Calvary Cemetery (and their fitted CLG components) superimposed on a Day diagram, where the position of the coercivity spectrum (approximately) corresponds to the position of the sample on the Day diagram. The graph also lists the abundance estimates for the pedogenic component $\left(f_{\text {ped }}\right.$ (constrained CLG) from Figure 5), and samples with high abundances of fine-grained pedogenic particles tend to plot closer to the fine-grained SD field of the Day diagram. Despite a good mixing model [Dunlop, 2002a] that aids in the interpretation
Table 2. CLG Distribution Parameters for Samples Shown in Figures $3 a-6 a^{a}$

\begin{tabular}{|c|c|c|c|c|}
\hline \multirow[b]{2}{*}{ Depth,cm } & \multicolumn{2}{|c|}{ Pedogenic Component } & \multicolumn{2}{|c|}{ Background } \\
\hline & $\log \mathrm{Bh}$ & Dp & $\log \mathrm{Bh}$ & $\mathrm{Dp}$ \\
\hline \multicolumn{5}{|c|}{ Miriam Cemetery } \\
\hline 10 & 1.32 & 0.31 & 1.14 & 0.63 \\
\hline 20 & 1.35 & 0.31 & 1.07 & 0.64 \\
\hline 30 & 1.38 & 0.32 & 1.17 & 0.56 \\
\hline 40 & 1.32 & 0.36 & 1.02 & 0.74 \\
\hline 50 & 1.31 & 0.33 & 1.18 & 0.64 \\
\hline 60 & 1.32 & 0.30 & 1.22 & 0.59 \\
\hline 70 & 1.29 & 0.35 & 1.16 & 0.68 \\
\hline 80 & 1.30 & 0.32 & 1.20 & 0.62 \\
\hline 90 & 1.26 & 0.34 & 1.20 & 0.64 \\
\hline 100 & 1.29 & 0.34 & 1.18 & 0.64 \\
\hline 120 & 1.25 & 0.38 & 1.19 & 0.70 \\
\hline 160 & 1.26 & 0.39 & 1.20 & 0.78 \\
\hline 180 & 1.23 & 0.43 & 1.14 & 0.85 \\
\hline Average & $1.32 \pm 0.02$ & $0.31 \pm 0.02$ & $1.17 \pm 0.08$ & $0.66 \pm 0.08$ \\
\hline \multicolumn{5}{|c|}{ Prairie Pines } \\
\hline 5 & 1.35 & 0.32 & 1.11 & 0.66 \\
\hline 10 & 1.38 & 0.31 & 1.20 & 0.58 \\
\hline 15 & 1.33 & 0.34 & 1.14 & 0.68 \\
\hline 25 & 1.34 & 0.35 & 1.15 & 0.63 \\
\hline 35 & 1.38 & 0.31 & 1.21 & 0.57 \\
\hline 55 & 1.40 & 0.33 & 1.20 & 0.60 \\
\hline 75 & 1.44 & 0.29 & 1.23 & 0.56 \\
\hline 90 & 1.40 & 0.34 & 1.19 & 0.61 \\
\hline 115 & 1.34 & 0.44 & 1.10 & 0.67 \\
\hline 155 & 1.37 & 0.32 & 1.21 & 0.63 \\
\hline Average & $1.35 \pm 0.01$ & $0.33 \pm 0.01$ & $1.18 \pm 0.03$ & $0.62 \pm 0.02$ \\
\hline
\end{tabular}

\begin{tabular}{lcccc}
\multicolumn{5}{c}{ Mount Calvary Cemetery } \\
10 & $\mathbf{1 . 3 4}$ & $\mathbf{0 . 2 9}$ & $\mathbf{1 . 1 0}$ & $\mathbf{0 . 6 5}$ \\
20 & $\mathbf{1 . 3 1}$ & $\mathbf{0 . 3 2}$ & $\mathbf{0 . 9 8}$ & $\mathbf{0 . 8 6}$ \\
30 & $\mathbf{1 . 2 9}$ & $\mathbf{0 . 3 0}$ & $\mathbf{1 . 1 3}$ & $\mathbf{0 . 7 2}$ \\
40 & $\mathbf{1 . 3 3}$ & $\mathbf{0 . 3 0}$ & $\mathbf{1 . 1 4}$ & $\mathbf{0 . 6 6}$ \\
50 & $\mathbf{1 . 3 5}$ & $\mathbf{0 . 2 9}$ & $\mathbf{1 . 1 7}$ & $\mathbf{0 . 6 4}$ \\
60 & $\mathbf{1 . 3 2}$ & $\mathbf{0 . 3 8}$ & $\mathbf{1 . 0 7}$ & $\mathbf{0 . 7 6}$ \\
70 & 1.37 & 0.31 & $\mathbf{1 . 1 5}$ & $\mathbf{0 . 6 3}$ \\
80 & 1.36 & 0.34 & $\mathbf{1 . 1 3}$ & $\mathbf{0 . 6 7}$ \\
90 & 1.35 & 0.40 & $\mathbf{1 . 1 2}$ & $\mathbf{0 . 7 3}$ \\
100 & 1.41 & 0.30 & $\mathbf{1 . 2 3}$ & $\mathbf{0 . 5 9}$ \\
120 & 1.40 & 0.31 & $\mathbf{1 . 2 5}$ & $\mathbf{0 . 5 6}$ \\
140 & 1.37 & 0.39 & $\mathbf{1 . 2 2}$ & $\mathbf{0 . 6 3}$ \\
160 & 1.51 & 0.21 & $\mathbf{1 . 2 7}$ & $\mathbf{0 . 5 4}$ \\
180 & 1.40 & 0.22 & $\mathbf{1 . 2 7}$ & $\mathbf{0 . 6 0}$ \\
200 & 1.36 & 0.26 & $\mathbf{1 . 2 6}$ & $\mathbf{0 . 5 9}$ \\
Average & $1.32 \pm 0.02$ & $0.31 \pm 0.02$ & $1.17 \pm 0.08$ & $0.66 \pm 0.08$
\end{tabular}

\begin{tabular}{|c|c|c|c|c|}
\hline \multicolumn{5}{|c|}{ Honey Creek Conservation Area } \\
\hline 5 & 1.38 & 0.28 & 1.16 & 0.57 \\
\hline 15 & 1.33 & 0.33 & 1.17 & 0.64 \\
\hline 35 & 1.35 & 0.26 & 1.19 & 0.57 \\
\hline 55 & 1.34 & 0.32 & 1.16 & 0.61 \\
\hline 75 & 1.38 & 0.33 & 1.19 & 0.60 \\
\hline 95 & 1.42 & 0.38 & 1.15 & 0.60 \\
\hline 115 & 1.40 & 0.44 & 0.88 & 0.59 \\
\hline 135 & 1.43 & 0.37 & 1.19 & 0.60 \\
\hline 160 & 1.38 & 0.45 & 0.71 & 0.45 \\
\hline 200 & 1.35 & 0.46 & 0.75 & 0.69 \\
\hline Average & $1.36 \pm 0.01$ & $0.30 \pm 0.02$ & $1.2 \pm 0.2$ & $0.59 \pm 0.06$ \\
\hline
\end{tabular}

${ }^{\mathrm{a} B}$ Bold values indicate samples used for the averaging process.

of the hysteresis data a quantitative interpretation of these data is difficult because:

[35] 1. In addition to the presence of fine SD and coarse MD particles, the position of a sample on the Day diagram is influenced by the presence of ultrafine SP particles, and changes in magnetic mineralogy. 


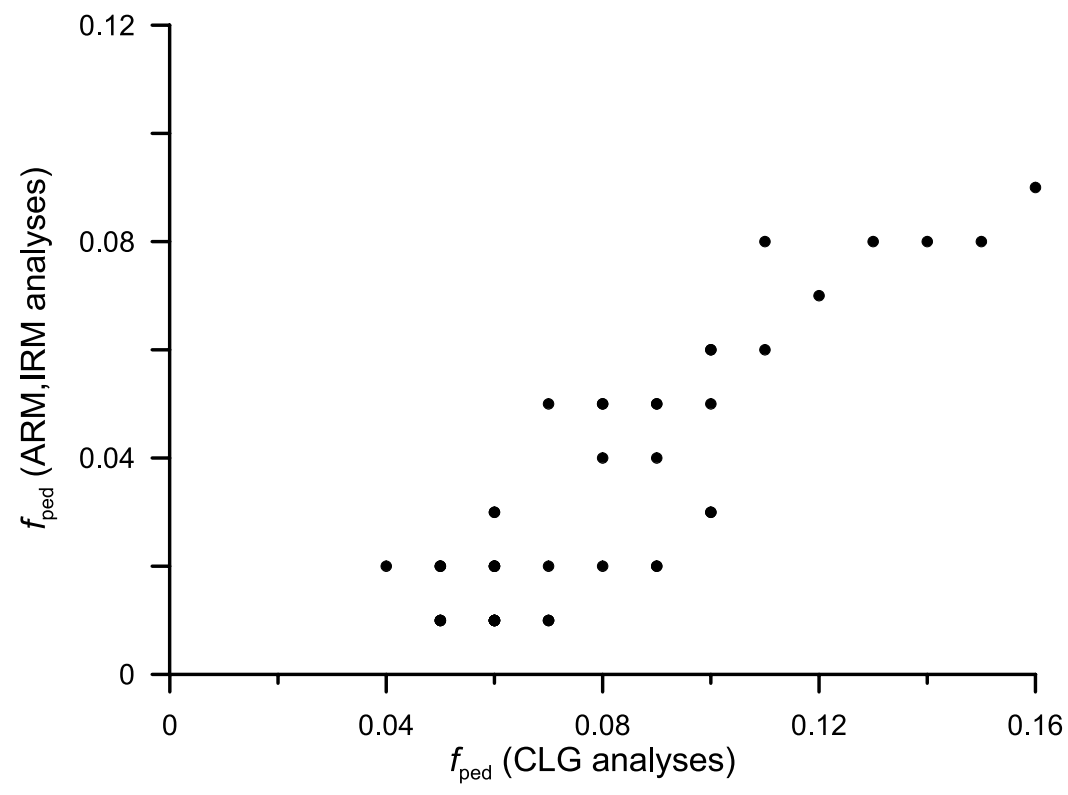

Figure 8. Comparison of abundance estimates of the pedogenic component obtained from constrained CLG analyses with abundance estimates obtained from analyses of ARM and IRM. The systematically higher abundances obtained from CLG analyses, but otherwise good correlation between the two estimates suggest that these analyses are sensitive to a wider range of particles. All pedogenic abundances $\left(f_{\text {ped }}\right)$ are calculated as a fraction of the total remanence carrying ferrimagnetic component.

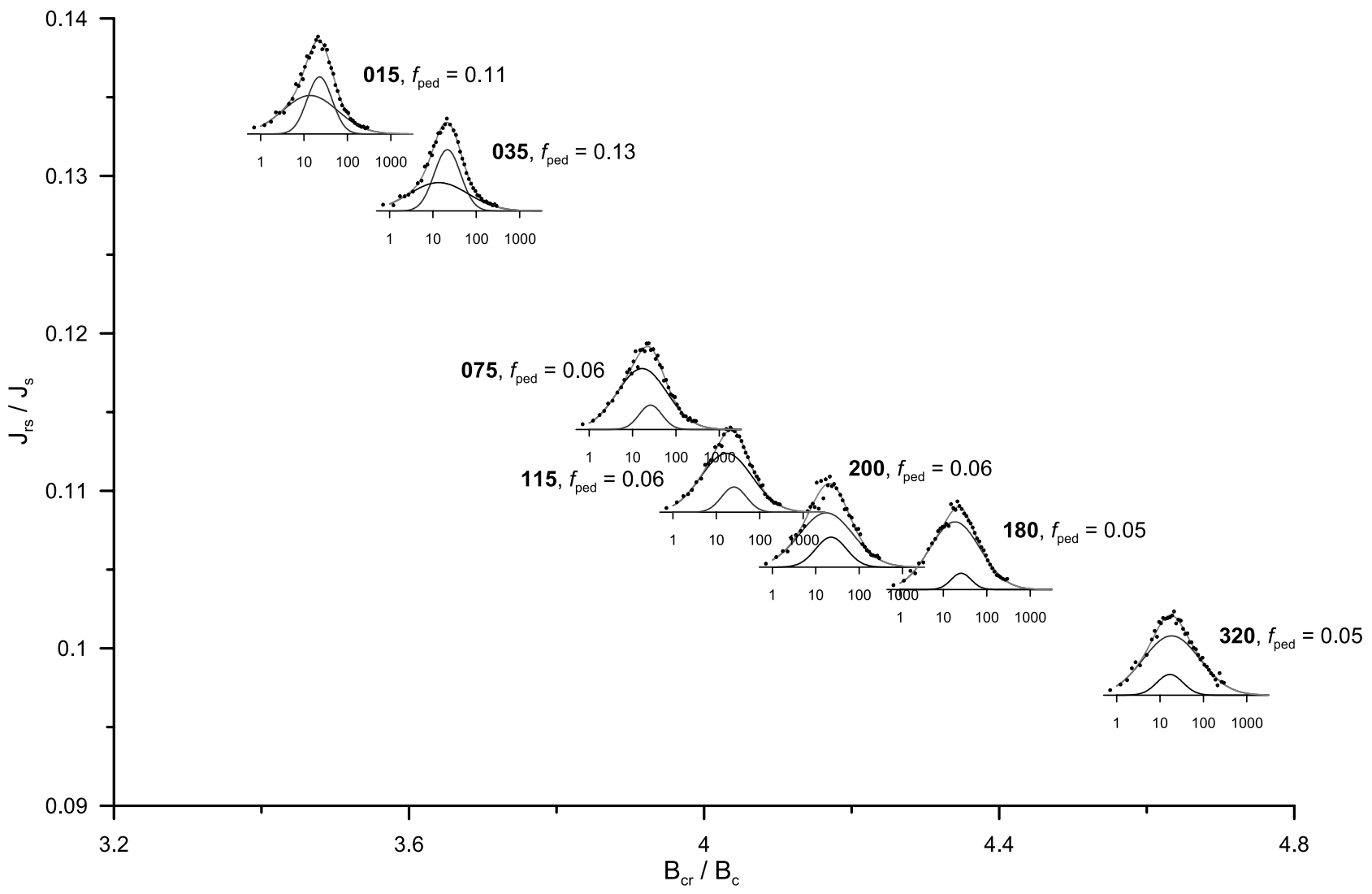

Figure 9. Coercivity spectra for several samples from site MTC 03-A superimposed on a Day diagram. Sample depths are given in bold numbers; also added are abundance estimates of the pedogenic component (from Figure 5). The vertical scale in the coercivity spectra varies from sample to sample to highlight the relative abundances of the two coercivity components, rather than their absolute abundances, which do not influence the position of the sample on the day diagram. 


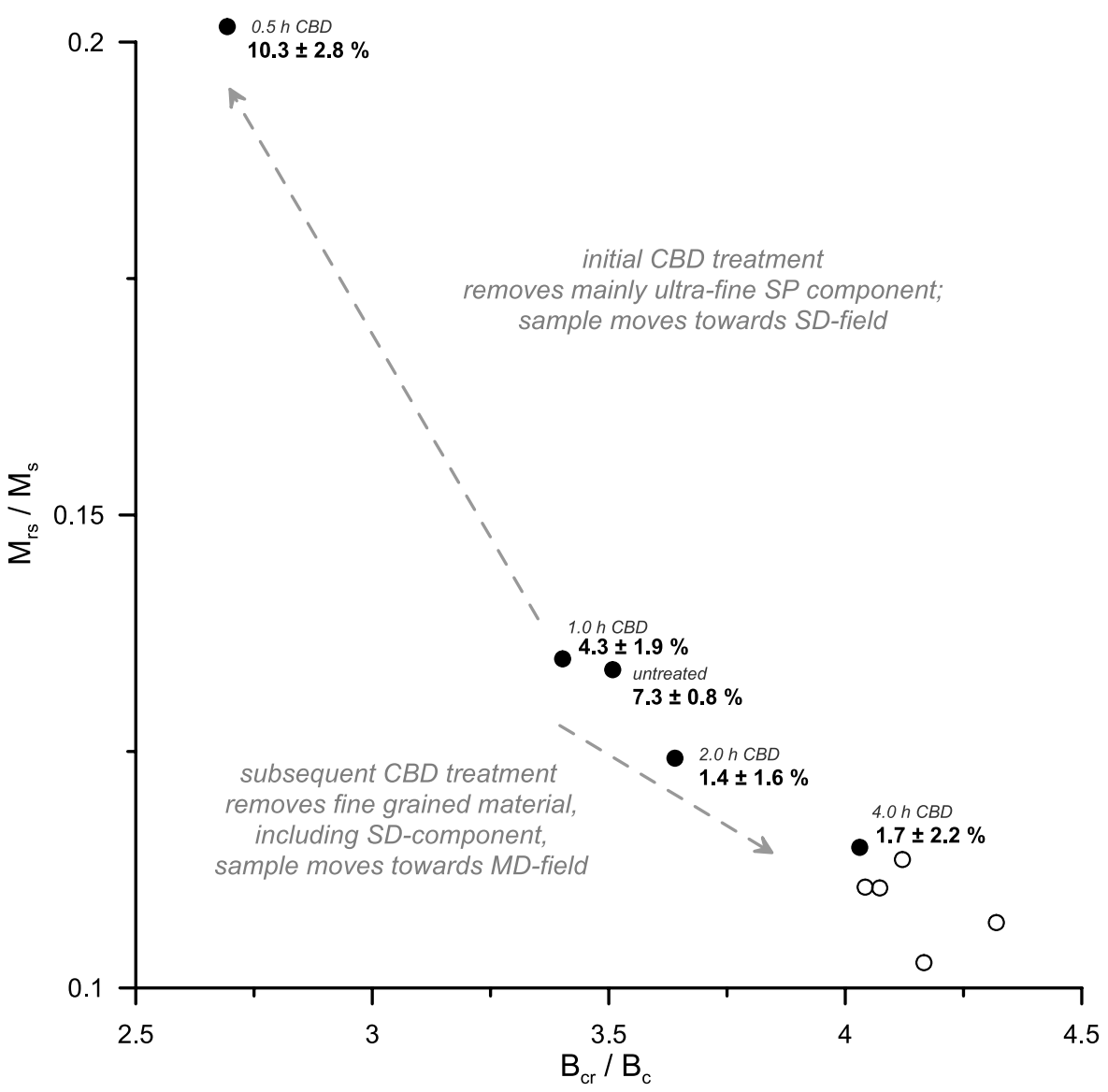

Figure 10. Effects of CBD treatment on a magnetically enhanced sample (MTC 03-A 15-25 cm, solid circles) and a sample from the unaltered parent material (MTC 03-A 230-250 cm, open circles). Successive removal of fine grains and maghemite leads to an initial move toward the SD field, followed by a move toward the MD field in the Day diagram. A sample from the parent material has very low initial concentrations of fine-grained SP and SD material and is little affected by CBD treatment. Frequency-dependent susceptibility values (in \%) are shown for all samples from MTC 03-A $15-25 \mathrm{~cm}$.

[36] 2. In order to arrive at quantitative estimates of the pedogenic component it is necessary to know the magnetic properties of the fine- and coarse-grained magnetic end-members.

[37] Figure 10 demonstrates the effects of SP particles, and probably the effects of maghemitization on the position of a sample in the Day plot. Two samples from site MTC 03-A were subjected to successive CBD dissolution treatments [Hunt et al., 1995b; Mehra and Jackson, 1960] which progressively remove maghemite as well as the SP and SD component of a sample. A sample from the magnetically enhanced horizon (MTC 03-A 15-25 cm, solid circles) shows an initial move toward the SD field of the Day diagram, which can be interpreted as the progressive removal of SP particles during the initial stages of the CBD treatment, and a subsequent move toward the MD field as SD and then coarser particles are dissolved. In contrast, the position of a sample from the unaltered parent material (MTC 03-A 230-250 cm, open circles) which starts out with a low abundance of fine grained SP and SD material is little affected by the successive treatment steps.

[38] Measurements of $\chi_{\mathrm{FD}}$, however, do not confirm this simple SP-SD-MD mixing model. $\chi_{\mathrm{FD}}$ values (in percent) for each CBD-treated sample from the magnetically enhanced horizon are shown in Figure 10. The untreated sample shows relatively high $\chi_{\mathrm{FD}}(7.3 \pm 0.8 \%)$, but initial CBD treatment increases $\chi_{\mathrm{FD}}$ to $10.3 \pm 2.8 \%$, suggesting an increase in SP particles. We are somewhat puzzled by the discrepancy between the hysteresis and $\chi_{\mathrm{FD}}$ results. Preferential removal of maghemite coatings might decrease the internal stresses caused by partial oxidation, lower $\mathrm{H}_{\mathrm{c}}$ and lead to shorter relaxation times $\tau$ which in turn would affect both the position of the samples on the Day plot as well as $\chi_{\mathrm{FD}}$. Similar puzzling results due to CBD treatment have been reported by Sun et al. [1995], who observed enhanced Hopkinson peaks when measuring Curie temperatures of CBD-treated samples. In any case, our results serve to underscore the complexity of the Day plot and the differences associated with its quantitative interpretation.

[39] Careful analyses of loessic soil profiles from the midwestern United States, which include measurements of $\chi_{\mathrm{FD}}[$ Geiss et al., 2004] and time-dependent IRM acquisition (Machac et al., submitted manuscript, 2006) show that the magnetically enhanced horizons contain mixtures of both SP and SD material, so a simple binary SD-MD mixing model is likely to underestimate the fine grained magnetic 


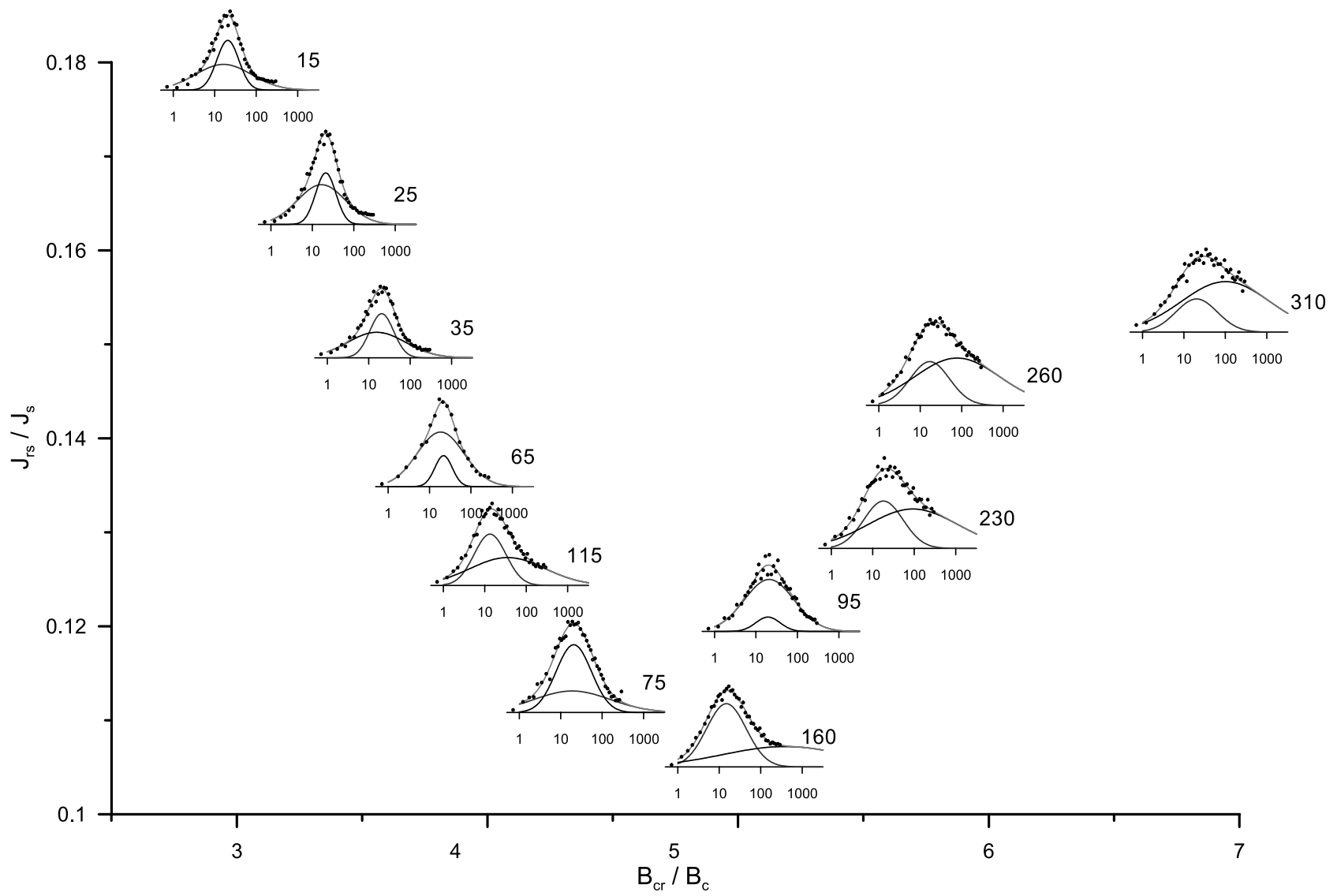

Figure 11. Effects of high-coercivity (antiferrimagnetic) minerals on hysteresis properties. Samples from the upper soil horizons fall on a SD-MD mixing line, but additions of a high-coercivity magnetic phase cause deeper samples to deviate from this line, making it possible to confuse mineralogical changes with changes in grain size.

fraction, even if the hysteresis properties of the end-members were known.

[40] Figure 11 shows a series of coercivity spectra superimposed on a Day diagram, similar to the ones shown in Figure 9 from Davisdale Conservation Area, Missouri. Samples from the upper soil horizons follow a SD-MD mixing line, similar to the samples shown in Figure 9. Samples from lower soil horizons, however, move off this mixing line due to the addition of a high-coercivity phase, which is clearly seen in the coercivity spectra. This change in mineralogy may easily be mistaken as an addition of SP material to the $\mathrm{C}$ horizon, because in the absence of samples with intermediate admixtures of antiferrimagnetic minerals (or measured coercivity spectra) the hematite or goethiterich end-members fall closely onto SD-SP mixing lines derived by Dunlop [2002b]. A detailed soil description of this site shows that the mineralogical changes in these lower samples are linked to the presence of redoximorphic features which are likely due to seasonal fluctuations in the water table in this shallow loess deposit.

[41] To further characterize the nature of this highcoercivity phase, we employed a series of alternating field (AF) and thermal demagnetization steps as suggested by Carter-Stiglitz et al. [2006] (Figure 12). To qualitatively distinguish between hematite and goethite, the sample is first magnetized at room temperature in a magnetic field of
$5 \mathrm{~T}$. The remanence contributions of magnetite and other low-coercivity ferrimagnetic minerals are then removed by demagnetizing the sample in an alternating magnetic field (peak field of $200 \mathrm{mT}$ ). Figure $12 \mathrm{a}$ shows a schematic representation of the subsequent thermal demagnetization procedure. Starting from room temperature the sample is first cooled through the Morin transition which removes remanence contributions due to hematite (feature 1 in thermal demagnetization curve shown in Figure 12a). Further cooling down to $20 \mathrm{~K}$ is used to test for the presence of goethite. The gain in remanence with decreasing temperature (feature 2 in Figure 12a) is a qualitative proxy for the presence of goethite [Dekkers, 1989]. Warming the sample through the Néel temperature of goethite up to $400 \mathrm{~K}$ (feature 3 in Figure 12a) removes (most) remanence contributions due to goethite. Final cooling (feature 4 in Figure $12 \mathrm{a})$ to $20 \mathrm{~K}$ checks the efficiency of the two demagnetization procedures.

[42] Low-temperature analyses of six samples from Davisdale Conservation Area show that samples again fall into two groups. Samples following the PSD-MD mixing line in Figure 11 show low-temperature properties similar to the upper, solid curve in Figure 12b. Here the antiferromagnetic component consists of a mixture of hematite (small loss of remanence through the Morin transition) and goethite (marked gain in remanence with decreasing 

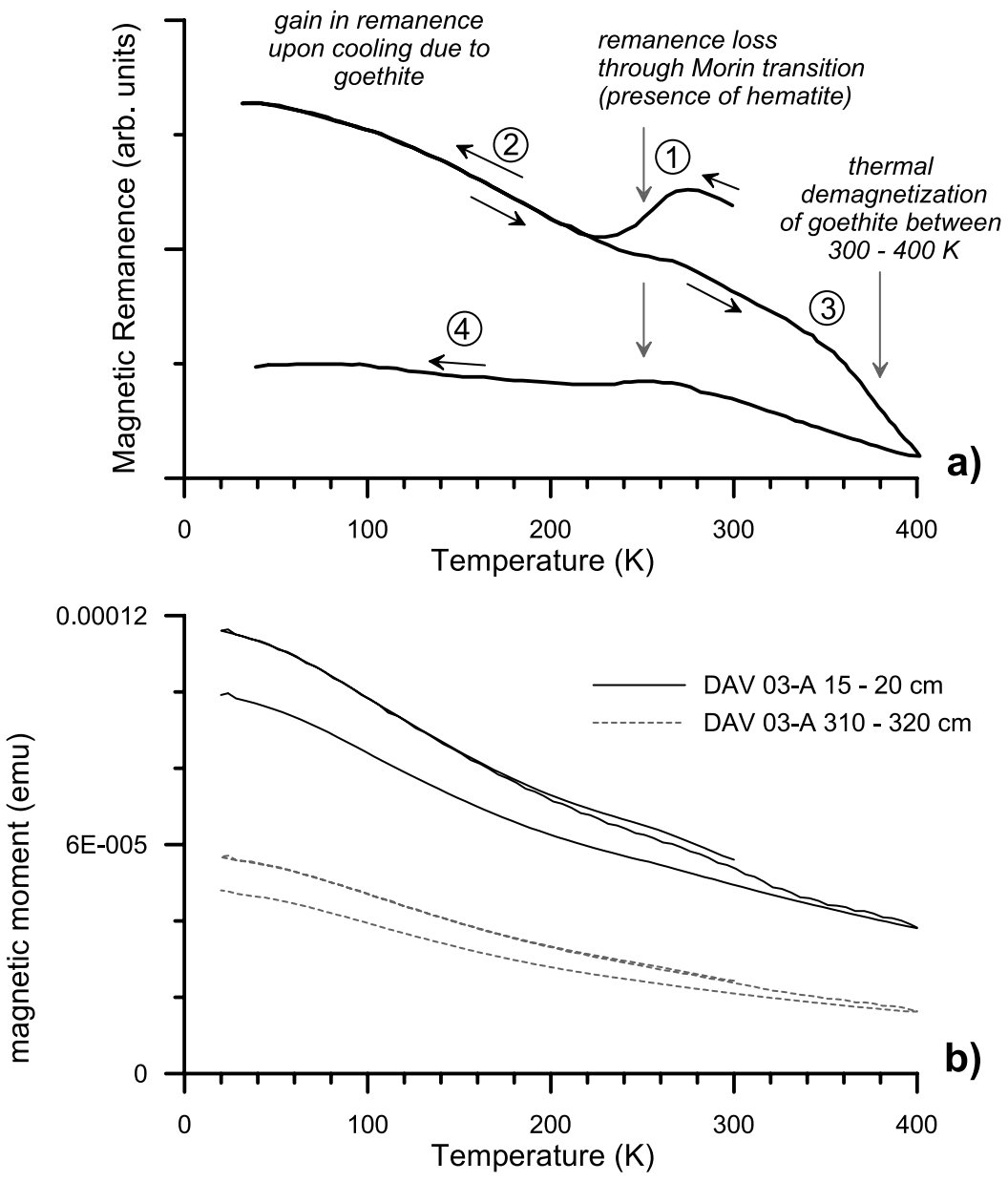

Figure 12. Thermal demagnetization curves to characterize the mineralogy of the antiferromagnetic component after Carter-Stiglitz et al. [2006]. (a) Idealized demagnetization curve describing the features used for mineral identification. Circled 1-4 are referred to in the text. (b) Two thermal demagnetization curves for Davisdale Conservation area. For further information, see text.

temperature, drop in remanence upon heating above $300 \mathrm{~K}$ ). Samples that drift away from this mixing line have lowtemperature characteristics similar to the lower, dashed curve in Figure 12b. The antiferromagnetic component of these samples is devoid of hematite and consists mainly of goethite.

[43] It should be noted that a quantitative interpretation of Figure 12 is difficult without further analyses. Poorly crystalline or ion substituted hematite may not be completely demagnetized through the Morin transition, and it is obvious from the rise in magnetic remanence during final cooling that goethite was only partially demagnetized when heated above its Néel temperature of $120 \mathrm{~K}$ [Özdemir and Dunlop, 1996]. However, the remaining remanence is small (6\%), compared to IRM acquired at $100 \mathrm{mT}$ (see Table 3) for samples dominated by low-coercivity ferrimagnets and increases down core (up to $23 \%$ ). The remaining SIRM is unlikely due to significant amounts of ferrimagnetic minerals with coercivities above $200 \mathrm{mT}$. Comparing IRM acquired at $100 \mathrm{mT}$ (a measure of low-coercivity ferrimagnetic minerals) and SIRM (acquired at $5 \mathrm{~T}$ ) after $\mathrm{AF}$ demagnetization (a measure of the remaining high-coercivity antiferromagnets) shows a relative increase in antiferro-

Table 3. Remanence Properties for Selected Samples From Davisdale, California

\begin{tabular}{cccccc}
\hline $\begin{array}{c}\text { Depth, } \\
\mathrm{cm}\end{array}$ & $\begin{array}{c}\mathrm{IRM}_{100 \mathrm{mT}}, \\
\mathrm{A} \mathrm{m}^{2} / \mathrm{kg}\end{array}$ & $\begin{array}{c}\mathrm{SIRM}_{5} \mathrm{~T} \\
\left(\text { After AFD) } \mathrm{A} \mathrm{m}^{2} / \mathrm{kg}\right.\end{array}$ & $\begin{array}{c}\text { Hard } \\
\text { IRM/Soft IRM }\end{array}$ & $\begin{array}{c}\mathrm{SIRM}_{5} \mathrm{~T} \\
\text { (After AFD and LTD), A m } / \mathrm{kg}\end{array}$ & $\begin{array}{c}\text { Remaining } \\
\text { Percent }\end{array}$ \\
\hline $15-20$ & $3.73 \times 10^{-3}$ & $2.65 \times 10^{-4}$ & 0.07 & $2.35 \times 10^{-4}$ & 6.3 \\
$35-40$ & $2.88 \times 10^{-3}$ & $2.11 \times 10^{-4}$ & 0.07 & $1.78 \times 10^{-4}$ & 6.2 \\
$75-80$ & $2.07 \times 10^{-3}$ & $1.83 \times 10^{-4}$ & 0.09 & $1.42 \times 10^{-4}$ & 6.9 \\
$115-120$ & $1.16 \times 10^{-3}$ & $1.48 \times 10^{-4}$ & 0.13 & $1.20 \times 10^{-4}$ & 10.4 \\
$230-240$ & $6.68 \times 10^{-4}$ & $1.33 \times 10^{-4}$ & 0.20 & $1.14 \times 10^{-4}$ & 17.1 \\
$310-320$ & $4.33 \times 10^{-4}$ & $1.15 \times 10^{-4}$ & 0.27 & $9.97 \times 10^{-5}$ & 23.0 \\
\hline
\end{tabular}




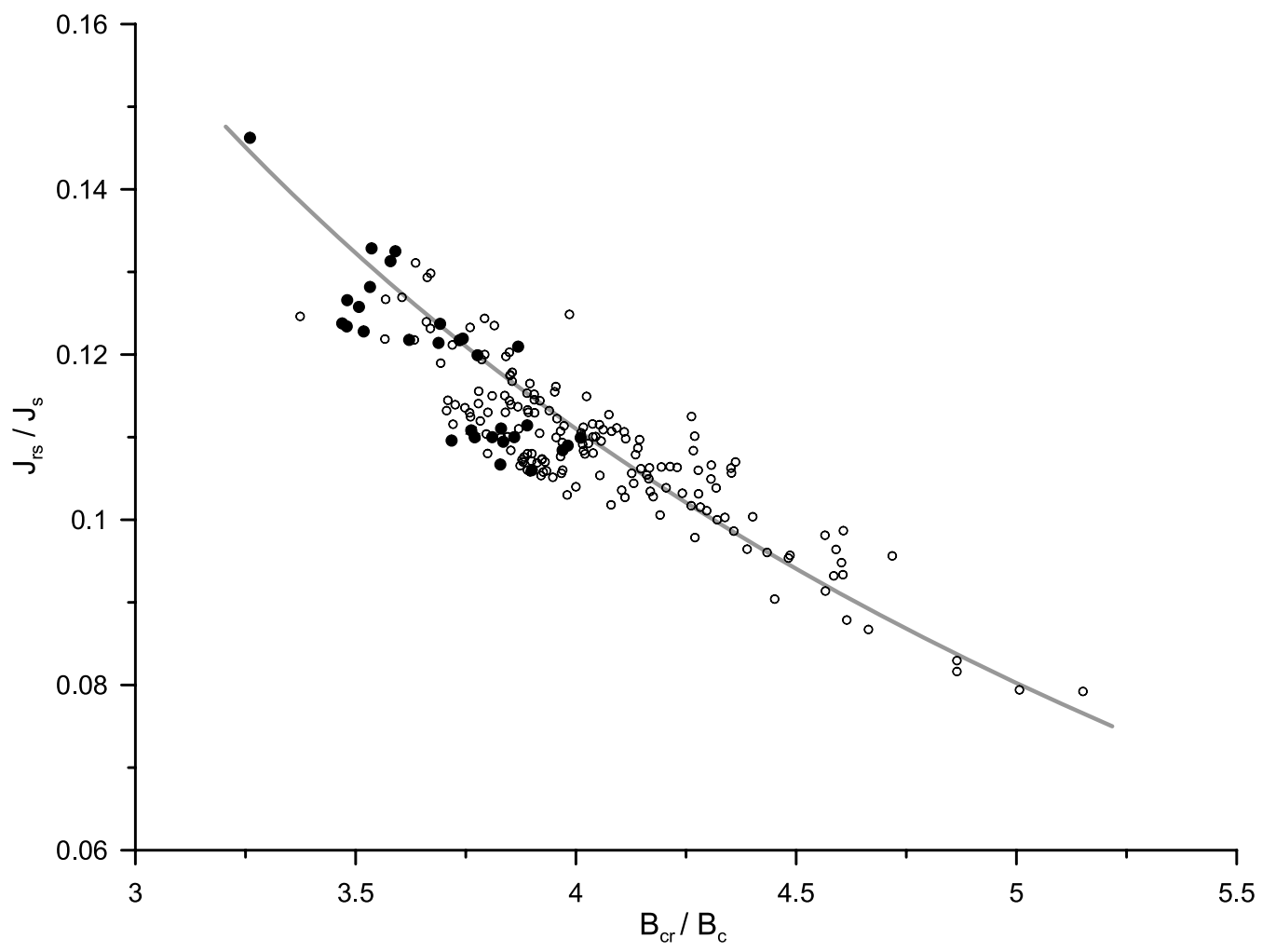

Figure 13. Hysteresis properties of selected sites with only small changes in magnetic mineralogy within the soil profile. Samples from magnetically enhanced horizons are shown as solid symbols. Samples from the parent material are shown as open symbols. All samples fall closely onto a PSD-MD mixing line (shaded curve). The hysteresis properties of the two end-members are given in Table 4.

magnetic minerals (Table 3 ) that is qualitatively consistent with the coercivity spectra shown in Figure 11.

[44] Despite these limitations, Figure 13 shows that samples from sites without significant changes in highcoercivity mineral concentrations fall closely onto a SDMD (or PSD-MD) mixing line, and it is possible to roughly constrain the abundance of fine-grained pedogenic material from hysteresis data. Magnetically enhanced samples (solid circle), in general, plot closer to the SD part of the diagram than samples from the parent material (open circle). The overlap between magnetically enhanced and unenhanced samples is due to site specific differences in the original parent material and varying degree of magnetic enhancement between sites. Our analysis of coercivity spectra shows that all samples, even samples from the $\mathrm{C}$ horizon, contain varying amounts of fine-grained pedogenic material, either because it was contained within the unaltered loess deposits or due to low level pedogenesis during loess deposition. Since the hysteresis properties of the background component are unknown we anchor our mixing line at the most MD-like sample of the entire distribution and assume a PSD pedogenic end-member to fit the general sample trend. The hysteresis properties of both endmembers are listed in Table 4. Keeping the position of both end-members the same for all sites is justified by our previous findings of a pedogenic component with relatively homogenous magnetic properties and allows for the initial presence of fine grained magnetite in the parent material. By determining the position of a sample along the mixing line shown in Figure 13 we can estimate the relative increase of fine-grained material in the magnetically enhanced horizons and compare it to estimates derived earlier. These estimates are listed in the tables contained in Figures 3-6 $\left(f_{\text {ped }}\right.$ hysteresis).

\subsection{Abundance of the Pedogenic Component}

[45] The tables in Figures 3-6 list our relative abundance estimates of pedogenic magnetite based on three different two-end-member models and one unconstrained CLG fitting algorithm. Since our CLG fitting algorithm does not delineate a pedogenic component per se (this interpretation is based on the analysis of all IRM demagnetization curves from a soil profile), we only compare the abundance estimates from models with two constrained end-members.

[46] All three techniques show the same general grain size trends. Magnetically enhanced samples are characterized by an addition of finer grained pedogenic material. Our estimates of the absolute amount depends mainly on the technique used for the estimate. This is not surprising, since all three methods are sensitive to slightly different grain size

Table 4. Assumed Hysteresis Properties for Pedogenic and Background Fractions

\begin{tabular}{lcc}
\hline & $\mathrm{B}_{\mathrm{cr}} / \mathrm{B}_{\mathrm{c}}$ & $\mathrm{J}_{\mathrm{rs}} / \mathrm{J}_{\mathrm{s}}$ \\
\hline Pedogenic component & 1.43 & 0.34 \\
Background component & 5.2 & 0.075 \\
\hline
\end{tabular}


or coercivity ranges. Evaluating ARM and IRM values is probably the best predictor for the abundance of SD particles, while the interpretation of IRM demagnetization curves is likely to be sensitive to a wider range of particles (SD-PSD). Our analysis of hysteresis data suffered from lack of knowledge regarding the hysteresis properties of the pedogenic end-member. The choice of one set of endmembers for all sites likely leads to an overestimation of the pedogenic component, which might be partially offset by the presence of SP particles in the magnetically enhanced horizons. This is especially true for sites whose parent material plots relatively far away from the MD field.

[47] While absolute abundance estimates may vary widely among techniques, relative changes in abundance are remarkably consistent between techniques. Estimates for the relative increase in abundance ranges from $2-3 \%$ of the ferrimagnetic component for Miriam Cemetery, 2-4\% for Prairie Pines, $6-8 \%$ for Mount Calvary Cemetery, and $3-6 \%$ for Honey Creek Conservation Area. Therefore relatively small additions of pedogenic magnetite (or maghemite) of about $5 \%$ can explain the observed changes in concentration and grain-size-dependent parameters.

[48] Evans and Heller [1994] estimate the abundance of ferrimagnetic minerals (magnetite and maghemite) in Chinese loess to be approximately $0.05 \%$, which rises to $0.2 \%$ in the strongly developed S3 paleosol at Baoji. A study of a loess/paleosol sequence from the central Chinese loess plateau by Spassov et al. [2003] finds that slightly oxidized pedogenic magnetite contributes approximately $2 / 3$ of the IRM in paleosols. In loess, $90 \%$ of the IRM signal is due to detrital magnetite with hematite contributing most of the remaining $10 \%$. Loess from the midwestern United States contains similar amounts of ferrimagnets $(0.04-0.06 \%)$, but modern soils are far less magnetic. The best developed soils analyzed in our study, which developed in relatively weakly magnetized loess along the Missouri loess bluffs, contain up to $0.07 \%$ of ferrimagnetic material. The contribution of pedogenic magnetite to IRM ranges between $40 \%$ and $55 \%$ which is slightly less but comparable to the pedogenic contributions reported by [Spassov et al., 2003].

\subsection{Size Distribution of the Pedogenic Component}

[49] Our study of three grain size proxies confirms the fine-grained nature of the pedogenic magnetic component which straddles the SP-SD grain size boundary. Since our analyses are limited to measurements of magnetic remanence our data suggest that a large fraction of the pedogenic component consists of SD-sized ferrimagnetic minerals (magnetite of maghemite), but our choice of remanence parameters (lower $\alpha_{\mathrm{ASD}}$ than originally expected), necessary to fit the observed data, suggests a somewhat wider grain size range. This interpretation is confirmed by analyses of coercivity spectra. The coercivity distribution of the pedogenic component is similar to the coercivity distribution of synthetic Wright-4000 magnetite (now likely to be partially oxidized to maghemite) with an average particle diameter of approximately $0.05 \mu \mathrm{m}(\ddot{\mathrm{O}}$. Özdemir, personal communication, 1998).

[50] On the basis of the tight clustering of data on a Day diagram, Dunlop [2002b] suggests that there is little evidence for a significant SP contribution to the pedogenic component of Chinese paleosols. This is not the case for the modern soils studied here. Soil samples from the midwestern United States fall into a region of the Day plot where they are fitted equally well by mixtures of (P)SD and MD, or (P)SD and SP particles. However, rock magnetic studies [Geiss et al., 2004; Machac et al., submitted manuscript, 2006] show the presence of SP particles or particles straddling the SP-SD grain size boundary which is consistent with previous findings from loess/paleosol sequences worldwide [e.g., Banerjee et al., 1993; Forster et al., 1994; Liu et al., 2005; Maher and Taylor, 1988; Maher and Thompson, 1991; Özdemir and Banerjee, 1982; Zhou et al., 1990]. The relatively tight cluster of hysteresis data for magnetically enhanced samples is more likely caused by similar grain size distributions within the pedogenic component rather than the absence of a SP component.

[51] Perhaps the most surprising result of our study is the uniformity of the pedogenic component throughout our study area. All our sites have been chosen for their uniform parent material (Peoria loess), similar landscape position (stable uplands) and age (Holocene), but climatic conditions and vegetation cover vary significantly across our transect. Pedogenic components with relatively uniform magnetic properties have been reported previously for the Chinese loess plateau [Evans and Heller, 1994; Eyre and Shaw, 1994, Egli, 2004] and loess sequences in Hungary and Tajikistan [Forster and Heller, 1997]. However, Peoria loess is derived from several different sources [Muhs and Bettis, 2000] with varying magnetic properties and it is reasonable to assume that the difference in parent material influences the magnetic properties of the pedogenic component at least to some degree. However, the magnetic properties of the pedogenic component can be described reasonably well through one set of remanence acquisition efficiencies (Figure 2) or a very narrow set of CLG distribution parameters (Figure 7).

[52] This uniformity of the pedogenic magnetic component found in loessic soils from several sites around the world is strongly suggestive of a common enhancement mechanism for these sites. Ultrafine magnetite has been synthesized under soil-like conditions by Taylor et al. [1987], but uniform grain size distributions require tight control of experimental conditions. Formation of pedogenic magnetite then either occurs under a very limited set of soil conditions which is unlikely given the wide range of climatic regimes under which these soils form, or the conditions of pedogenic magnetite formation are, directly or indirectly, controlled by biological activity. Evans and Heller [1994] recognized the similarity between pedogenic magnetite and fossil magnetosomes reported by Petersen et al. [1986]. Fassbinder et al. [1990] found such bacteria in a Bavarian wetland soil, but magnetotactic bacteria are rarely detected [Dearing et al., 2001] in the well-drained soils that show significant amounts of magnetic enhancement and are preferred for paleoclimatic reconstruction. Liu et al. [2005] point out that intracellularly produced magnetite crystals are unlikely to result in the observed distribution of grain sizes, but the formation of SP-sized particles could be due to the conversion of poorly crystalline iron phases into highly magnetic ferrimagnets mediated by dissimilatory ironreducing bacteria [Maher and Thompson, 1999]. In a recent study, Guyodo et al. [2006] were able to correlate magnetically enhanced soil horizons with higher microbial bio- 
mass, but failed to detect a common group of dissimilatory iron-reducing bacteria (Geobacteraceae). Nevertheless, in our opinion a biologically mediated origin of the pedogenic magnetic component is highly likely.

[53] There is evidence [Jacobs and Mason, 2005] that some of the thick A horizons observed in Peoria loess are due to the incorporation of Holocene loess into the modern soil profile. In theory, the addition of magnetically homogenous loess into the soil profile could cause a magnetic signal similar to the one described in this study. It should be noted, however, that the magnetic properties of the (relatively) unaltered Peoria loess, which was likely deposited under much more homogenous conditions than the later Holocene additions, has a much more diverse magnetic signal than the pedogenic component extracted in our study. We therefore think that this magnetic component is truly pedogenic, rather than due to the incorporation of younger loess into the soil profile.

\section{Conclusions}

[54] Our analysis of modern loessic soil profiles from the midwestern United States yielded the following results.

[55] 1. Relatively small amounts of fine-grained ferrimagnetic material can explain the concentration- and grain-sizedependent properties of the magnetically enhanced soil horizons. Our estimates of the amount of pedogenic material varied based on the magnetic proxies used, but in general, all sites required an addition of less than 10\% (by volume) of fine (mostly SD sized) magnetite or maghemite. Estimates based on ARM and IRM values required the smallest amount of pedogenic material, while estimates based on hysteresis properties depended strongly on the chosen model parameters. The systematic differences are due to varying grain size sensitivities amongst the used proxies.

[56] 2. While the abundance of pedogenic magnetite increases roughly with mean annual precipitation [Geiss and Zanner, 2006] its magnetic characteristics remain nearly constant. ARM/IRM ratios for all sites can be reconstructed using one set of remanence acquisition efficiencies, CLG analyses of IRM demagnetization curves extract a pedogenic component with a narrow range of distribution parameters, and hysteresis data from sites unaffected by gleying and seasonably high water tables plot closely on one (P)SD-MD mixing line. The similarity of the pedogenic component argues strongly for one magnetic enhancement process acting over a wide range of precipitation conditions (mean annual precipitation $440-1000 \mathrm{~mm} / \mathrm{yr}$ ).

[57] 3. Our interpretations of grain-size-dependent magnetic proxies are consistent with a pedogenic component consisting of a mixture of SP, SD, and possibly PSD particles. This includes hysteresis data, whose interpretation is complicated by the opposing effects of SP and SD particles, as well as changes in mineralogy, on the position of a sample on the Day diagram.

[58] Acknowledgments. We would like to thank the numerous land owners and state agencies who generously granted us access to sites in Nebraska, Iowa, and Missouri over the past 5 years. Jim Bisbee, Daniel Scollan, Alex Masi, and Saroj Aryal were of invaluable help in the field and in the lab. Their work was supported by grants from Trinity College. Comments by S. K. Banerjee and an anonymous reviewer helped to significantly improve the manuscript. Some magnetic measurements were performed at the Institute for Rock Magnetism at the University of Minnesota. We would like to thank its fabulous staff for their hospitality, ideas, suggestions, and all the effort that goes into running a great lab. Finally, we would like to mention that the IRM is funded by the W. M. Keck Foundation, the National Science Foundation's Earth Science Division's Instrumentation and Facilities Program, and the University of Minnesota.

\section{References}

Banerjee, S. K. (1994), Contributions of fine-particle magnetism to reading the global paleoclimate record, J. Appl. Phys., 75, 5925-5930.

Banerjee, S. K., C. P. Hunt, and X.-M. Liu (1993), Separation of local signals from the regional paleomonsoon record of the Chinese loess plateau: A rock-magnetic approach, Geophys. Res. Lett., 20, 843-846.

Begét, J. E., and D. B. Hawkins (1989), Influence of orbital parameters on Pleistocene loess deposition in central Alaska., Nature, 337, 151-153.

Carter-Stiglitz, B., S. K. Banerjee, A. Gourlan, and E. Oches (2006), A multi-proxy study of Argentina loess: Marine oxygen isotope stage 4 and 5 environmental record from pedogenic hematite, Paleogeogr. Paleoclimatol. Paleoecol., 239(1-2), 45-62.

Day, R., M. Fuller, and V. A. Schmidt (1977), Hysteresis properties of titanomagnetites: Grain-size and compositional dependence, Phys. Earth Planet. Inter., 13, 260-267.

Dearing, J. A., P. M. Bird, R. J. L. Dann, and S. F. Benjamin (1997), Secondary ferrimagnetic minerals in Welsh soils: A comparison of mineral magnetic detection methods and implications for mineral formation, Geophys. J. Int., 130, 727-736

Dearing, J. A., J. A. Hannam, A. S. Anderson, and E. M. H. Wellington (2001), Magnetic, geochemical and DNA properties of highly magnetic soils in England, Geophys.l J. Int., 144, 183-196.

Dekkers, M. J. (1989), Magnetic properties of natural goethite-II. TRM behaviour during thermal and alternating field demagnetization and low-temperature treatment, Geophys. J., 97, 341-355.

Dunlop, D. J. (2002a), Theory and application of the Day plot $\left(M_{r s} / M_{s}\right.$ versus $\left.H_{c r} / H_{c}\right)$ : 1 . Theoretical curves and tests using titanomagnetite data, J. Geophys. Res., 107(B3), 2056, doi:10.1029/2001JB000486.

Dunlop, D. J. (2002b), Theory and application of the Day plot $\left(M_{r s} / M_{s}\right.$ versus $\left.H_{c r} / H_{c}\right): 2$. Application to data for rocks, sediments, and soils, J. Geophys. Res., 107(B3), 2057, doi:10.1029/2001JB000487.

Egli, R. (2003), Analysis of the field dependence of remanent magnetization curves, J. Geophys. Res., 108(B2), 2081, doi:10.1029/ 2002JB002023.

Egli, R. (2004), Characterization of individual rock magnetic components by analysis of remanence curves, 1. Unmixing natural sediments, Stud. Geophys. Geod., 48, 391-446.

Evans, M. E., and F. Heller (1994), Magnetic enhancement and paleoclimate: Study of a loess/paleosol couplet across the loess plateau of China Geophys. J. Int., 117, 257-264.

Eyre, J. K., and J. Shaw (1994), Magnetic enhancement of Chinese loess: The role of $\gamma \mathrm{Fe}_{2} \mathrm{O}_{3}$ ?, Geophys. J. Int., 117, 265-271.

Fassbinder, J. W. E., H. Stanjek, and H. Vali (1990), Occurrence of magnetic bacteria in soil, Nature, 343, 161-163.

Feng, Z.-D., W. C. Johnson, Y.-C. Lu, and P. A. Ward III (1994), Climatic signals from loess-soil sequences in the central Great plains, USA, Paleogeogr. Paleoclimatol. Paleoecol., 110, 345-358.

Forster, T., and F. Heller (1997), Magnetic enhancement paths in loess sediments from Tajikistan, China and Hungary, Geophys. Res. Lett., 24, $17-20$.

Forster, T., M. E. Evans, and F. Heller (1994), The frequency dependence of low field susceptibility in loess sediments, Geophys. J. Int., 118, 636-642.

Geiss, C. E., and C. W. Zanner (2006), Sediment magnetic signature of climate in modern loessic soils from the Great Plains, Quat. Int., in press.

Geiss, C. E., C. E. Umbanhowar, P. Camill, and S. K. Banerjee (2003), Sediment magnetic properties reveal Holocene climate change along the Minnesota prairie-forest ecotone, J. Paleolimnol., 30, 151-166.

Geiss, C. E., C. W. Zanner, S. K. Banerjee, and J. Minott (2004), Signature of magnetic enhancement in a loessic soil in Nebraska, United States of America, Earth Planet. Sci. Lett., 228(3/4), 355-367.

Grygar, T., M. J. Dekkers, P. Bezdicka, O. Schneeweiss, J. Dedecek, and P. P. Kruiver (2003), Iron oxide mineralogy in late Miocene red beds from La Gloria, Spain: Rock-magnetic, voltammetric and Vis spectroscopy analyses, Catena, 53, 115-132.

Guyodo, Y., T. M. LaPara, A. J. Anschutz, R. L. Penn, S. K. Banerjee, C. E. Geiss, and C. W. Zanner (2006), Rock magnetic, chemical and bacterial community analysis of a modern soil from Nebraska, Earth Planet. Sci. Lett., 251, 168-178.

Heller, F., and M. E. Evans (1995), Loess magnetism, Rev. Geophys, 33, $211-240$. 
Heller, F., and T. S. Liu (1984), Magnetism of Chinese loess deposits, Geophys. J. R. Astron. Soc., 77, 125-141.

Heller, F., and T. S. Liu (1986), Paleoclimatic and sedimentary history from magnetic susceptibility of loess in China, Geophys. Res. Lett., 13, $1169-1172$.

Heller, F., C. D. Shen, J. Beer, T. S. Liu, A. Bronger, M. Suter, and G. Bonani (1993), Quantitative estimates of pedogenic ferromagnetic mineral formation in Chinese loess and paleoclimatic implications, Earth Planet. Sci. Lett., 114, 385-390.

Heslop, D., M. J. Dekkers, P. P. Kruiver, and I. H. M. van Oorschot (2002), Analysis of isothermal remanent magnetization acquisition curves using the expectation-maximization algorithm, Geophys. J. Int., 148, 58-64.

Heslop, D., G. McIntosh, and M. J. Dekkers (2004), Using time- and temperature-dependent Preisach models to investigate the limitations of modelling isothermal remanent magnetization acquisition curves with cumulative log Gaussian functions, Geophys. J. Int., 157, 55-63.

Hunt, C. P., B. M. Moskowitz, and S. K. Banerjee (1995a), Magnetic properties of rocks and minerals, in Rock Physics and Phase Relations A Handbook of Physical Constants, AGU Ref. Shelf, vol. 3, edited by T. J. Aherns, pp.189-204, AGU, Washington, D. C.

Hunt, C. P., M. J. Singer, G. Kletetschka, J. Ten Pas, and K. L. Verosub (1995b), Effect of citrate-bicarbonate-dithionite treatment on fine-grained magnetite and maghemite, Earth Planet. Sci. Lett., 130, 87-94.

Jacobs, P. M., and J. A. Mason (2005), Impact of Holocene dust aggradation on A horizon characteristics and carbon storage in loess-derived Mollisols of the Great Plains, USA, Geoderma, 125, 95-106.

Jenny, H. (1941), Factors of Soil Formation, A System of Quantitative Pedology, 281 pp., McGraw-Hill, New York.

Kletetschka, G., and S. K. Banerjee (1995), Magnetic stratigraphy of Chinese loess as a record of natural fires, Geophys. Res. Lett., 22, $1241-1343$.

Kruiver, P. P., and H. F. Passier (2001), Coercivity analysis of magnetic phases in sapropel S1 related to variations in redox conditions, including an investigation of the $S$ ratio, Geochem. Geophys. Geosyst., 2(12) doi:10.1029/2001GC000181.

Kruiver, P. P., M. J. Dekkers, and D. Heslop (2001), Quantification of magnetic coercivity components by the analysis of acquisition curves of isothermal remanent magnetization, Earth Planet. Sci. Lett., 189, $269-276$

Kukla, G. (1988), The mystery of the Chinese magnetic dust, LamontDoherty Geol. Obs. Yearb. 88, pp. 32-37, Lamont-Doherty Geol. Obs. Palisades, N. Y.

Kukla, G., F. Heller, X. M. Liu, T. C. Xu, T. S. Liu, and Z. S. An (1988), Pleistocene climates in China dated by magnetic susceptibility, Geology, $16,811-814$

Le Borgne, E. (1955), Susceptibilite magnetique anormale du sol superficiel, Ann. Geophys., 11, 399-419.

Le Borgne, E. (1960), Influence du feu sur les proprietes magnetiques du sol et sur celles du schiste et du granite, Ann. Geophys., 16, 159-195.

Liu, Q., J. Torrent, B. A. Maher, Y. Yu, C. Deng, R. Zhu, and X. Zhao (2005), Quantifying grain size distribution of pedogenic magnetic particles in Chinese loess and its significance for pedogenesis, J. Geophys. Res., 110, B11102, doi:10.1029/2005JB003726.

Lu, H., T. Liu, Z. Gu, B. Liu, L. Zhou, J. Han, and N. Wu (2000), Effect of burning $\mathrm{C} 3$ and $\mathrm{C} 4$ plants on the magnetic susceptibility signal in soils, Geophys. Res. Lett., 27, 2013-2016

Maher, B. A. (1986), Characterization of soils by mineral magnetic measurements, Phys. Earth Planet. Inter., 42, 76-92.

Maher, B. A. (1998), Magnetic properties of modern soils and Quaternary loessic paleosols: Paleoclimatic implications, Paleogeogr. Paleoclimatol. Paleoecol., 137, 25-54

Maher, B. A., and R. M. Taylor (1988), Formation of ultrafine-grained magnetite in soils, Nature, 336, 368-370.

Maher, B. A., and R. Thompson (1991), Mineral magnetic record of the Chinese loess and paleosols, Geology, 19, 3-6.

Maher, B. A., and R. Thompson (1992), Paleoclimatic significance of the mineral magnetic record of the Chinese loess and paleosols, Quat. Res. $37,155-170$.

Maher, B. A., and R. Thompson (1999), Paleomonsoons I: The magnetic record of paleoclimate in the terrestrial loess and paleosol sequences, in Quaternary Climates, Environments and Magnetism, edited by B. A.
Maher and R. Thompson, pp. 81-125, Cambridge Univ. Press, New York.

Maher, B. A., R. Thompson, and L. P. Zhou (1994), Spatial and temporal reconstructions of changes in the Asian paleomonsoon: A new mineralmagnetic approach, Earth Planet. Sci. Lett., 125, 461-471.

Maher, B. A., R. Thompson, and M. W. Hounslow (1999), Introduction to Quaternary Climates, Environments and Magnetism, in Ouaternary Climates, Environments and Magnetism, edited by B. A. Maher and R. Thompson, pp.1-48, Cambridge Univ. Press, New York.

Mehra, O. P., and M. L. Jackson (1960), Iron oxide removal from soils and clays by a dithionate-citrate system buffered with sodium bicarbonate, Clays Clay Miner., 7, 317-327.

Muhs, D. R., and E. A. I. Bettis (2000), Geochemical variations in Peoria loess of western Iowa indicate paleowinds of midcontinental North America during last glaciation, Quat. Res., 53, 49-61.

Mullins, C. E. (1977), Magnetic susceptibility of the soil and its significance in soil science: A review, J. Soil Sci., 28, 223-246.

Oches, E. A., and S. K. Banerjee (1996), Rock-magnetic proxies of climate change from loess-paleosol sediments of the Czech Republic, Stud. Geophys. Geod., 40, 287-300

Özdemir, Ö., and S. K. Banerjee (1982), A preliminary magnetic study of soil samples from west-central Minnesota, Earth Planet. Sci. Lett., 59, $393-403$.

Özdemir, Ö., and D. Dunlop (1996), Thermoremanence and Néel temperature of goethite., Geophys. Res. Lett., 23, 921-924.

Petersen, N., T. von Dobeneck, and H. Vali (1986), Fossil bacterial magnetite in deep-sea sediments from the South Atlantic Ocean, Nature, 320, $611-615$.

Robertson, D. J., and D. E. France (1994), Discrimination of remanencecarrying minerals in mixtures, using isothermal remanent magnetization acquisition curves, Phys. Earth Planet. Inter., 82, 223-234.

Schwertmann, U. (1988), Occurrence and formation of iron oxides in various pedoenvironments, in Iron in Soils and Clay Minerals, edited by J. W. Stucki, B. A. Goodman, and U. Schwertmann, pp. 276-308, Springer, New York.

Singer, M. J., and P. Fine (1989), Pedogenic factors affecting magnetic susceptibility of northern California soils, Soil Sci. Soc. Am. J., 53, 1119-1127.

Soil Survey Division Staff (1993), Soil Survey Manual, 437 pp., U.S. Govt. Print. Off., Washington, D. C.

Spassov, S., F. Heller, R. Kretzschmar, M. E. Evans, L. P. Yue, and D. K. Nourgaliev (2003), Detrital and pedogenic magnetic mineral phases in the loess/paleosol sequence at Lingtai (Central Chinese Loess Plateau), Phys. Earth Planet. Inter., 140, 255-275.

Stockhausen, H. (1998), Some new aspects for the modelling of isothermal remanent magnetization acquisition curves by cumulative log Gaussian functions, Geophys. Res. Lett., 25, 2217-2220.

Sun, W.-W., S. K. Banerjee, and C. P. Hunt (1995), The role of maghemite in the enhancement of magnetic signal in the Chinese loess-paleoso sequence: An extensive rock magnetic study combined with citrate-bicarbonate-dithionite treatment, Earth Planet. Sci. Lett., 133, 493-505.

Taylor, R. M., B. A. Maher, and P. G. Self (1987), Magnetite in soils: I. The synthesis of single-domain and superparamagnetic magnetite, Clay Miner., 22, 411-422.

Worm, H. U. (1999), Time dependent IRM: A new technique for magnetic granulometry, Geophys. Res. Lett., 26, 2557-2560.

Yamazaki, T., and N. Ioka (1997), Cautionary note on magnetic grain-size estimation using the ratio of ARM to magnetic susceptibility, Geophys. Res. Lett., 24, 751-754.

Zhou, L. P., F. Oldfield, A. G. Wintle, S. G. Robinson, and J. T. Wang (1990), Partly pedogenic origin of magnetic variations in Chine loess, Nature, 346, 737-739.

C. E. Geiss, Department of Physics, Trinity College, 105 McCook Hall, 300 Summit St., Hartford, CT 06106, USA. (christoph.geiss@trincoll.edu)

C. W. Zanner, Department of Soil, Water, and Climate, University of Minnesota, 439 Borlaug Hall, 1991 Upper Buford Circle, St. Paul, MN 55108, USA. (bzanner@umn.edu) 